\title{
Tfap2a is a novel gatekeeper of differentiation in renal progenitors during kidney development
}

\author{
Brooke E. Chambers ${ }^{1}$, Gary F. Gerlach ${ }^{1}$, Karen H. Chen ${ }^{1}$, Eleanor G. Clark ${ }^{1}$, Ignaty Leshchiner ${ }^{2}$,
} Wolfram Goessling ${ }^{2}$, and Rebecca A. Wingert ${ }^{1 *}$

${ }^{1}$ Department of Biological Sciences, Center for Stem Cells and Regenerative Medicine, Center for Zebrafish Research, University of Notre Dame, Notre Dame, 46556, USA

${ }^{2}$ Brigham and Women's Hospital, Genetics and Gastroenterology Division, Harvard Medical School, Harvard Stem Cell Institute, Boston, MA 02215, USA

Keywords: kidney, nephron, segmentation, differentiation, tfap2a, tfap2b, irx3b, irx1a, zebrafish

Key Abbreviations: branchio-oculo-facial syndrome (BOFS); corpuscle of Stannius (CS); distal early (DE); distal late (DL); fluorescent whole mount in situ hybridization (FISH); immunofluorescence (IF); iroquois homeobox 1a (irx1a); iroquois homeobox 3b (irx3b); hours post fertilization (hpf); mesenchymal to epithelial transition (MET); morpholino oligonucleotide (MO); proximal convoluted tubule (PCT); proximal straight tubule (PST); somite stage (ss); thick ascending limb (TAL); transcription factor AP-2 alpha (tfap2a); transcription factor AP-2 beta (tfap2b); whole mount in situ hybridization (WISH); wild-type (WT)

Correspondence: Rebecca A. Wingert, Ph.D., Department of Biological Sciences, University of Notre Dame, 100 Galvin Life Sciences, Notre Dame, IN 46556, USA; Email: rwingert@nd.edu, Phone: (574)631-0907, Fax: (574)-631-7413 


\section{Summary Statement}

Here, we report for the first time that transcription factor AP-2 alpha (tfap2a) controls the progression from nephron progenitor into the fully differentiated state. This fundamentally deepens our knowledge about the genetic control of kidney development.

\section{Abstract}

Renal functional units known as nephrons undergo patterning events during development that create a segmental array of cellular populations with discrete physiological tasks. Knowledge about the terminal differentiation programs of each nephron segment has central importance for understanding kidney disease and to advance regenerative medicine, as mammalian nephrons grown in organoid cultures from pluripotent cells fail to terminally differentiate. Here, from a novel forward genetic screen using zebrafish we report the discovery that transcription factor AP-2 alpha (tfap2a) coordinates a gene regulatory network that controls the progression of nephron distal segment progenitors into the differentiated state. Overexpression of tfap2a rescued differentiation in mutants and caused ectopic expression of distal segment markers in wild-type nephrons, indicating tfap2a is sufficient to instigate the distal segment differentiation program. tfap2a/2b deficiency exacerbated distal nephron segment differentiation defects, revealing functional redundancy where tfap $2 a$ has a dominant role upstream of its family member. With further genetic studies, we assembled a blueprint of the tfap2a gene regulatory network during nephrogenesis. We demonstrate that tfap2a acts downstream of Iroquois homeobox $3 b$, a conserved distal lineage transcription factor. tfap2a controls a circuit consisting of irx $1 a$, tfap $2 b$, and genes encoding solute transporters that dictate the specialized metabolic functions of the distal nephron segments, and we show for the first time that this regulatory node is distinct from the pathway circuits controlling aspects such as apical-basal polarity and ciliogenesis during the differentiation process. Thus, our studies reveal new insights into the genetic control of differentiation, where tfap2a regulates the suite of segment transporter traits. These findings have relevance for understanding renal birth defects, as well as efforts to recapitulate nephrogenesis in vivo to make functional units that can facilitate organoid applications such as drug discovery and regenerative therapies. 


\section{Introduction}

Vertebrate kidney ontogeny involves the reiterative formation and degradation of several structures from the intermediate mesoderm: the pronephros, the mesonephros, and the metanephros (Saxen, 1987). In amniotes, the metanephros serves as the final kidney form, while in lower vertebrates, such as fish and frogs, the mesonephros functions as the adult kidney. Importantly, all the kidney versions are comprised of conserved functional units called nephrons (Dressler, 2006). The nephron is comprised of a blood filter, a segmented epithelial tubule, and a collecting duct. Each of these anatomical nephron parts modifies the filtrate in a stepwise fashion to perform the vital tasks of excretion, $\mathrm{pH}$ balance, and fluid homeostasis. Occurring in approximately 1 in 500 births, Congenital Anomalies of the Kidney and Urinary Tract (CAKUT) are among the most common birth defects and are the primary cause of pediatric end stage renal disease (ESRD) (Airik and Kispert, 2007; Song and Yosypiv, 2011). The shared etiology across these diverse conditions is the aberrant development of nephrons stemming from genetic dysregulation (Schedl, 2007). To this end, it is imperative to understand the signals that coordinate nephron formation during renal organogenesis.

The zebrafish pronephros has emerged as a genetically tractable vertebrate model to study the molecular mechanisms regulating nephron segment development events (Wingert et al., 2007; Wingert and Davidson, 2008; Wingert and Davidson, 2011). The embryonic zebrafish is transparent in nature, and its pronephric kidney is structurally simple, consisting of two bilateral nephrons that make it an excellent model to study renal progenitor changes in vivo (Naylor et al., 2017). Like other vertebrate nephrons, the zebrafish pronephros is patterned into distinct proximal and distal epithelial segments (Wingert et al., 2007; Wingert and Davidson, 2008). Further, zebrafish mirror fundamental processes of mammalian nephron formation such as the mesenchymal to epithelial transition (MET) of renal progenitors, establishment of apical-basal polarity, lumen formation, ciliogenesis, and formation of specialized segment populations (Gerlach and Wingert, 2013). While there has been significant progress in understanding nephron segment patterning in recent years (Desgrange and Cereghini, 2015; Lindström et al., 2015; Chung et al., 2017), the pathways that dictate segmental terminal differentiation are far from understood.

Transcription factors play a central role in operating the genetic networks that orchestrate renal cell fate acquisition and nephron segment patterning (Desgrange and Cereghini, 2015; Lindström et al., 2015). Advances in single-cell RNA sequencing and gene expression analysis in both the embryonic murine and human kidneys have brought to light an inventory of factors mapped to distinct regions of developing nephrons (Lindström et al., 2018a,b). Although these studies have provided a detailed transcription factor localization atlas that is time-dependent, the functions of these factors in nephrogenesis have not yet been fully elucidated. One uncharacterized gene is Transcription Factor AP-2 Alpha (TFAP2A), which clustered with developing medial/distal tubule signatures (Lindström et al., 2018b). TFAP2A is a member of the AP-2 transcription factor family (AP-2 $\alpha, A P-2 \beta, A P-2 \gamma, A P-2 \delta$ and $A P-2 \varepsilon)$, whose proteins share highly 
102

103

104

105

106

conserved dimerization and DNA binding motifs across vertebrates (Fig. S1). AP-2 factors bind to GC-rich promoter sequences, and can homodimerize and heterodimerize with one another (Eckert et al., 2005). During development, these factors have been shown to exercise redundant and unique functions depending on the tissue context (Eckert et al., 2005).

Tfap2a and family member Tfap $2 b$ also have overlapping expression patterns during vertebrate embryogenesis in neural crest derivatives, surface ectoderm, and the kidney (Moser et al., 1997; Knight et al., 2003; Knight et al., 2005). Surprisingly, the elimination of Tfap2a and Tfap $2 b$ in mice results in completely different phenotypic outcomes. Tfap2a knockout mice die perinatally and display a suite of pleiotropic features that include craniofacial alterations, incomplete neural tube closure, hypoplastic hearts and kidneys (Schorle et al., 1996; Zhang et al., 1996; Brewer and Williams, 2004; Brewer et al., 2004). In contrast, Tfap $2 b$ null mice exhibit patent ductus arteriosus and die shortly after birth due to acute renal failure with elevated apoptosis (Moser et al., 1997; Hilger-Eversheim et al., 2000; Wang et al., 2018). Because Tfap $2 b$ mutants exhibit less severe phenotypes, this factor is proposed to share redundant functions with Tfap2a during development (Eckert et al., 2005; Kerber et al., 2001). An example in support of this relationship is that Tfap2a plays a more dominant role than Tfap $2 b$ in the development of branchial arches in mice (Van Otterloo et al., 2018).

Genetic defects in the AP-2 factors are associated with several human diseases. Autosomal dominant TFAP2A mutations in humans cause branchio-oculo-facial syndrome (BOFS), which primarily affects craniofacial tissue (Milunsky et al., 2008). Additionally, human TFAP2A lesions are associated with multicystic dysplastic kidney defects, but the mechanisms have remained unexplored. Dominant-negative mutations in human TFAP2B cause Char Syndrome, which affects heart, face, and limb development (Satoda et al., 2000). Despite the previously documented renal phenotypes associated with Tfap2a and Tfap $2 b$ deficiency in rodents, these factors have not been studied further in the context of kidney development. For example, nephron segmentation has not been analyzed in either Tfap2a or Tfap2bdeficient murine models. Nevertheless, Tfap2a/tfap2a has been extensively studied in the vertebrate neural crest, where it facilitates specification and differentiation through a complex genetic regulatory network (Knight et al., 2003; Knight et al., 2005; Holzschuh et al., 2003; Barrallo-Gimeno et al., 2003; O'Brien et al., 2004; Li and Cornell, 2007; Hoffman et al., 2007; Van Otterloo et al., 2010; de Crozé et al., 2011; Wang et al., 2011; Bhat et al., 2012; Green et al., 2014; Kantarci et al., 2015; Seberg et al., 2017). These studies provide a valuable framework with which to consider the roles of Tfap2a/tfap2a in other tissues, where it is likely to also mediate genetic networks.

Here, we report the novel zebrafish nephron segment mutant, terminus (trm), which was isolated in a forward haploid genetic screen. Employing whole genome sequencing, we identified a mutation that blocks proper splicing of tfap2a. While tfap2a deficient nephrons have normal distal segment pattern formation, 
display normal epithelial polarity and cilia development, they experience a block in other aspects of terminal differentiation, resulting in the loss of solute transporter expression within distal segments. Interestingly, tfap2a is sufficient to induce ectopic expression of distal segment markers in adjacent segment domains. We found that tfap $2 b$ functions redundantly and downstream of tfap $2 a$ to turn on the distal nephron solute transporter program. Further, tfap2a articulates with the Iroquois homeobox transcription factors irx $1 a$ and irx $3 b$, which are regulators of intermediate/distal nephron identity. Our study reveals for the first time that tfap2a controls a gene regulatory network that serves as a gatekeeper of terminal differentiation during nephron segment development, and establishes a new paradigm that will be valuable to deepen our knowledge of cell differentiation mechanisms in the kidney.

\section{Results}

\section{Forward genetic screen identifies tfap2a as a novel regulator of nephron development}

There remain many gaps in our understanding of the genetic blueprint needed to orchestrate renal stem cell fate decisions and nephron segment formation during kidney ontogeny. The embryonic zebrafish kidney, or pronephros, is a practical genetic model for nephron segmentation (Gerlach and Wingert, 2013). At 24 hours post fertilization (hpf), the pronephros is fully formed and exhibits a very simple organization consisting of two parallel nephrons (Fig. 1A), making cellular changes easy to detect (Poureetezadi and Wingert, 2016). Each nephron is comprised of a blood filter, a series of proximal and distal segments that reabsorb and secrete molecules, and a collecting duct to transport waste (Fig. 1A) (Wingert et al., 2007).

To identify novel renal regulators, we performed a forward genetic haploid screen in zebrafish. We obtained maternal gametes from the F1 generation, applied ultraviolet light inactivated sperm to generate F2 haploid embryos, and assayed them for nephron segment defects by whole mount in situ hybridization (WISH) (Kroeger et al., 2014). For our assay we applied a mixture of probes that specifically localize to alternating compartments of the pronephros: podocytes (wt1b), proximal convoluted tubule (PCT) (s/c20a1a), and the distal early segment (DE) (slc12a1) (Fig. 1B). Through this multiplex assay we isolated the nephron mutant terminus (trm) which affected DE segment development based on abrogated slc12a1 expression within the pronephros (Fig. 1B).

We performed whole genome sequencing to identify the causative gene for the trm phenotype (Leshchiner et al., 2012). Using SNP track software analysis, the location of the genetic lesion was mapped to chromosome 24 (Fig. 1C). We used previously described thresholds to enrich results (Ryan et al., 2013) and discovered the gene tfap2a was a high scoring candidate at the chromosome 24 locus, where there 
was a $G$-> A substitution that was predicted to disrupt splicing at the splice donor site of exon 1 . We performed direct PCR sequencing on trm mutants and wild-type (WT) siblings, and confirmed this genetic change (Fig. 1C). To characterize how this mutation affected splicing, we conducted transcript analysis. RT-PCR on total RNA isolated from trm mutants revealed four aberrant tfap2a spliceoforms compared to WTs (Fig. 1D). One aberrant transcript encoded an in-frame addition of 38 amino acids (Fig. 1D), which may possess native function or have dysfunctions associated with protein folding or stability. The other three transcripts encoded premature stop codons (Fig. 1D). These aberrant trm transcripts are predicted to truncate the essential transcriptional activation and DNA binding domains in the Tfap2a protein (Fig. 1D).

Next, we explored whether the loss of tfap2a function in trm mutants was the sole origin of their renal phenotype. To do this, we performed complementation tests between trm and $\operatorname{tfap} 2 a^{m 819}$, the latter which encodes a nonsense allele, followed by phenotype assessment with WISH and finally genotyping analysis. Compound $\mathrm{trm}^{+/} ;$tfap $2 \mathrm{a}^{\mathrm{m819+/}}$ heterozygote embryos displayed the loss of romk2 expression within the pronephros DE segment and reduced $d / x 2$ expression in the neural crest as well (Fig. 1E). This result indicates that the alleles failed to complement one another, which most likely indicates that the same gene is affected, and provided powerful evidence that disruption of tfap2a expression alone underlies the trm phenotype.

Until now, tfap2a has been known as essential for neural crest and epidermis differentiation. Thus, we assessed whether trm mutants evinced hallmarks of tfap2a deficiency. With analysis of live morphology at $4 \mathrm{dpf}$, we found that trm developed abnormal craniofacial cartilage and pericardial edema, which was phenocopied upon tfap2a morpholino knockdown (Fig. 1F). RT-PCR analysis confirmed that this tfap2a MO effectively disrupts splicing (Fig. S2). We examined facial cartilage using Alcian blue staining, where we found trm possesses defects in Meckel's cartilage and pharyngeal arch structures (Fig. 1G). The cartilage phenotypes observed in trm are consistent with the documented neural crest tfap2a mutant alleles lockjaw and mont blanc (Knight et al., 2003; Barrallo-Gimeno et al., 2003). trm also displayed disrupted craniofacial vasculature formation as indicated by o-dianisidine staining (Fig. S4). Further, when we assayed for tfap2a protein by whole mount immunofluorescence (IF), we detected no pronephric expression in trm mutants as compared to WT at $24 \mathrm{hpf}$. The absence of tfap2a protein expression in the mutant pronephros indicates that the ultimate consequence of trm allele is a bona-fide loss-of-function. In light of the mutation site, these IF data further indicate that the tfap2a exon1c spliceoform encodes the dominant protein variant that is active during kidney development. In sum, these results show that trm mutants exhibit many features of tfap2a deficiency, and reveal for the first time that tfap2a is needed for nephrogenesis-specifically for proper emergence of the DE segment population. 

redundantly to induce regimens of distal segment solute transporter genes

214 Of the AP-2 family of transcription factors, only tfap2a and tfap $2 b$ have been reported as expressed in the developing zebrafish pronephros (Knight et al., 2005; Sugano et al., 2017). Zebrafish tfap2a and tfap2b genes are closely related, as they share overall 65\% amino acid sequence identity, with highly similar DNA-binding and transactivation domains in particular (Knight et al., 2005). The sequence of both tfap2a and tfap2b zebrafish genes are conserved with their respective vertebrate orthologues as well (Fig. S1) (Knight et al., 2005).

To further investigate the spatiotemporal expression domains of tfap2a and tfap $2 b$ within the developing renal field, we performed WISH with RNA antisense riboprobes over the time span of nephrogenesis. We found that $t f a p 2 a$ and $t f a p 2 b$ transcripts were expressed broadly in renal progenitors at the 10 somite stage (ss), however this expression became dynamically restricted to the distal region of the pronephros by the 28 ss (Fig. 2A). Through fluorescent in situ hybridization (FISH) studies, we confirmed that tfap2a and tfap $2 b$ were robustly co-expressed in nearly identical renal progenitor domains at the 10 ss (Fig. 2B). FISH at the 20 ss and 28 ss revealed that tfap2a had a mostly broader expression pattern across the distal pronephros compared to tfap2b (Fig. 2B), consistent with expression in the DE and DL segments. Differential tfap2a/b expression was noted rostrally and in the posterior pronephric duct region at the 20 ss and 28 ss, where only tfap2a transcripts were detected (Fig. 2B). Next, we sought to validate if tfap2a was expressed in the DE segment domain, which is demarcated by s/c12a1 expression, given the trm mutant phenotype (Wingert et al., 2007). tfap2a and slc12a1 transcripts were co-localized at the 28 ss (Fig. 2C). These results indicate that tfap2a and tfap $2 b$ expression occurs in renal progenitors during a developmental window that positions them as possible participants in distal nephron development.

To explore potential genetic relationships between tfap2a and tfap2b, we performed loss of function experiments. trm exhibited significantly reduced tfap $2 b$ expression in the distal pronephros and the hindbrain region (Fig. 2D). Conversely, knockdown of tfap2b using a morpholino (MO) strategy revealed that tfap2a expression was unaffected throughout the embryo, including the pronephros (Fig. 2E). The tfap2b MO tool was verified to interrupt splicing by RT-PCR, which revealed that it caused inclusion of intronic sequence that encoded a premature stop codon, which is predicted to generate a truncated peptide (Fig. S3). In combination, these genetic studies suggest a more dominant role of tfap2a in the context of nephrogenesis, placing tfap2a upstream of tfap2b.

Because tfap2a and tfap2b have been demonstrated to function redundantly in the development of other tissue types, we next wanted to determine if these two factors could act similarly during nephrogenesis (Knight et al., 2005; Van Otterloo et al., 2018; Seberg et al., 2017; Bassett et al., 2012; Jin et al., 2015). To interrogate this, we performed combination knockdown studies and assayed a set of solute transporters 
that characterize the distal nephron segments at $24 \mathrm{hpf}$ (Fig 3A). tfap2b deficiency alone had no detectable affects on distal solute transporter expression. trm and tfap2a morphants exhibited significant reductions in slc12a1, slc12a3, and clcnk expression as compared to WT (Fig. 3A,B,C,D). At 4 dpf, trm mutants still failed to express distal early solute transporters slc12a1 and romk2 (Fig. S4). However, the pronephros was functional between 2 and $3 \mathrm{dpf}$, based on assessment of renal clearance, which normally initiates during this time period, thereby ruling out developmental delay (Fig. S4). Knockdown of tfap2b in trm mutants caused a more severe slc12a3 reduction than tfap2a deficient embryos (Fig. 3). Interestingly, there was not a statistically significant reduction in the slc12a1 or clcnk domain length in tfap2b injected trm mutants versus tfap2a deficiency alone (Fig. 3). By comparison, tfap2a/2b morphants had statistically significant reduction of the s/c12a1, s/c12a3, and clcnk pronephros expression domains versus tfap2a deficiency alone. Notably, tfap2a morpholino targets all three splice variants, however the trm mutation only affects one of these splice variants (Fig. 1C). In light of this phenotypic spectrum, we concluded that the development of the distal nephron program is sensitive to the dosage of functional tfap2a/tfap $2 b$ alleles that are present. Taken together, these genetic studies reveal that the concerted action of tfap2a and tfap $2 b$ is necessary to fully turn on distal solute transporter programs, where tfap2a plays a more prominent role in this process upstream of $t f a p 2 b$.

\section{tfap2a is necessary and sufficient for DE differentiated cell expression signature}

Next, we wanted to determine if provision of WT tfap2a transcripts could specifically rescue the absence of DE solute transporter expression in trm. Activation of a heat-shock inducible tfap2a transgene at the 8 ss restored romk2 expression in trm mutants comparable to WT levels based on absolute length measurements (Fig. 4A). This result further underscores the conclusion that tfap2a deficiency is the single, specific cause of the trm phenotype. We then performed tfap2a gain of function studies by two independent methods: 1) employing an inducible hs:tfap2a transgenic line and 2) microinjection of tfap2a mRNA in WT embryos. When we overexpressed tfap2a by these approaches there was a significant expansion of the romk2 expression domain which normally marks the DE segment (Fig. 4B). All of the heat-shock treated $h s: t f a p 2 a$ transgenic embryos exhibited an expanded romk2 domain, while control nonheat-shocked embryos developed normal romk2 domains. About 9\% (12/132) of the tfap2a cRNA injected clutches presented with an increased romk2 domain, however about 64\% (85/132) of embryos were scored as dysmorphic. This lower phenotype penetrance, compared to the transgenic overexpression model, is likely caused by the toxic affects of tfap2a during early development, which has been reported to disrupt gastrulation ( $\mathrm{Li}$ and Cornell, 2007). Interestingly, ectopic romk $2^{+}$cells appeared to invade both the adjacent proximal and distal segment domains in these gain-of-function experiments.

To examine more closely if tfap2a overexpression was inducing neighboring nephron segments to convert to a DE program, we performed double FISH on heat-shocked $h s: t f a p 2 a$ embryos. We detected slc12a ${ }^{+}$ 
cells within the slc12a $3^{+} \mathrm{DL}$ domain (Fig. 4C). Upon closer analysis, these cells were found to coexpress both s/c12a1 and s/c12a3 transcripts (Fig. 4C'). Heat-shocked hs:tfap2a animals also possessed s/c12a ${ }^{+}$ cells spanning across the proximal domain that were coexpressing slc9a3 (Fig. 4D,D'). These phenotypes greatly contrast the WT situation, where there are sharp, clear boundaries between neighboring segment domains in the nephron (Fig. 4C,D). These results indicate that tfap2a overexpression is sufficient to sway the differentiation profile of proximal and distal late cell types by triggering the misexpression of DEspecific solute transporters.

\section{tfap2a drives DE terminal differentiation program}

Previous studies have demonstrated tfap2a can regulate terminal differentiation of various cell types including migratory neural crest, melanocytes, statoacoustic ganglion neurons, noradrenergic neurons, and the trophoblast lineage (Barrallo-Gimeno et al., 2003; Kantarci et al., 2015; Seberg et al., 2017; Greco et al., 1995; Kim et al., 2001; Pfisterer et al., 2001; Handwerger, 2009). This literature, in light of our loss of function and gain of function results, led us to hypothesize that tfap2a controls the terminal differentiation of distal nephron cells. To explore this notion, we first wanted to determine if the nephron segments were patterned correctly in trm mutants.

To assess the pattern formation of nephron segments in trm mutants, we performed double WISH to assess the segment domains located adjacent to the $\mathrm{DE}$, in this case the pan-proximal and DL. trm mutants exhibited a domain of slc9a3 expression comparable to WT embryos (Fig. 5A). In both WT and trm, this s/c9a3 ${ }^{+}$region was followed by a gap situated at the position normally occupied by the DE segment, and the s/c12a3 expression domain, which is smaller in trm mutants, immediately followed this gap (Fig. 5A). The intact sequence of the pan-proximal, gap/placeholder, and then the DL segment suggested that the DE segment 'footprint' was present in trm mutants, and thus that pattern formation had proceeded during nephrogenesis (Fig. 5A). Additionally, trm mutants exhibited no alterations in s/c20a1a or trpm7 expression domains, which mark the PCT and PST segments, respectively (Fig. S5). tfap2a morphants also developed normal proximal segments, as well as the DE footprint (data not shown). These results indicate that tfap2a deficient embryos undergo normal segmental patterning of the nephron tubule.

We then examined development of the corpuscle of Stannius in trm mutants, which is an endocrine gland situated between the DE and DL (Cheng and Wingert, 2015). We used WISH to assess the expression of transcripts encoding stanniocalcin 1 (stc1), a specific CS marker. Compared to WT embryos, trm mutants exhibited severely reduced stc1 expression (Fig. S5). In sum, these data rule out the occurrence of possible fate switches with adjacent nephron cell types that could account for the loss of the DE marker expression, and suggest that in addition to the DE, tfap2a may regulate CS lineage development and/or 
Next, we wanted to determine if trm mutant cells occupying the DE region were specified as kidney. To do this, we individually assayed for the expression of genes that are expressed robustly throughout the entire nephron tubule. Identical to WT embryos, trm mutants showed no gaps in expression of cdh 17 and $h n f 1 b a$, illustrating that mutant DE cells were fated to a kidney lineage identity (Fig. 5B). Further, we assessed if any alterations in cell proliferation or cell death occurs in response to loss of tfap2a. We detected no visible changes in the number of $\mathrm{pH}^{+}$cells within the DE domain of trm mutants compared to WT controls at 24 hpf (Fig. 5C). Additionally, there were no perceivable differences in the number of dying cells labeled with acridine orange in the distal pronephros compared to WTs at $24 \mathrm{hpf}$ (Fig. 5D).

Renal progenitor differentiation in the zebrafish pronephros is known to entail an MET of the mesenchymal progenitors, with establishment of polarity and lumen formation, as well as changes in cellular organelles such as cilia. Therefore, we sought to determine whether trm mutant DE cells exhibited any of these various differentiated features of the nephron tubular epithelium. Differentiated pronephros cells exhibit apical-basal polarity and form either a primary cilium or multiple cilia by the $24 \mathrm{hpf}$ stage (Gerlach and Wingert, 2013, 2014; McKee et al., 2014; Marra and Wingert 2016; Marra et al., 2016). We performed whole mount IF to analyze the expression of basolateral marker $\mathrm{Na}, \mathrm{K}-\mathrm{ATP}$ ase and the apical adaptor complex aPKC in the distal early region at $4 \mathrm{dpf}$. We found $\mathrm{Na}, \mathrm{K}-\mathrm{ATPase}$ and aPKC proteins were properly localized in trm mutants as compared to WT, therefore indicating that epithelial polarity was correctly established within the nephron tubules (Fig. 5E,E'). Further, trm mutants had a clearly discernible tubule lumen, indicating that tubulogenesis had proceeded analogous to WT embryos (Fig. 5E,E'). Next, we combined FISH of s/c12a1 with whole mount IF of acetylated tubulin to determine if cilia formation occurs within the mutant DE segment region. At $24 \mathrm{hpf}$, cilia arrangement and morphology in trm mutants was comparable to WT (Fig. 5F). This indicates that cilia assembly occurred normally in the mutant DE cells, which were visualized based on their nearly abrogated slc12a1 signal (Fig. 5F). Taken together, these data indicate that mutant DE cells exhibit mature epithelial qualities, however cannot fully turn on specific solute transporters, which are indicators of terminal differentiation and ultimately dictate segmentspecific physiological functions. From this, we conclude that trm mutants exhibit a unique block in the terminal differentiation of distal nephron cells, which involves the acquisition of segment-specific solute transporter proteins but is not linked to MET, polarity establishment, tubulogenesis or ciliogenesis programs.

\section{tfap2a functions downstream of irx $3 b$ and upstream of irx1a in the distal pronephros} We next wanted to understand the genetic relationship of tfap2a with known segment patterning factors, to establish the hierarchical regulation of tfap2a during distal segment development. Previous studies have 
respectively (Wingert and Davidson, 2008; Reggiani et al., 2007; Marra and Wingert, 2014). Because of this requirement, we first selected $i r x 3 b$ as a putative tfap2a gene regulatory network candidate for investigation.

To determine if tfap2a and irx $3 b$ are co-expressed during pronephros development, we performed double FISH studies. We found tfap2a and irx3b transcripts were co-localized in developing distal nephron cells at the 20 ss (Fig. 6A). Because of the tfap2a/irx3b overlapping expression patterns, we rationalized that these factors could be interacting in the same developmental pathway. Therefore, we performed knockdown experiments to determine potential pathway interactions between tfap2a and irx3b. Upon tfap2a knockdown, the irx3b expression domain was unchanged (Fig. 6B). However, upon irx3b knockdown, the tfap2a expression domain was significantly truncated (Fig. 6B,C). The regional loss of tfap2a transcripts in irx3b morphants equates to the DE segment address. We also observed a loss of tfap2a expression in migrating neural crest streams in irx3b morphants (Fig. 6B). To further validate if tfap2a acts downstream of $i r x 3 b$, we performed rescue experiments in irx3b morphants. Overexpression of the hs:tfap2a transgene was unable to rescue romk2 expression in irx3b knockdowns (data not shown). We postulate this is because irx3b-deficiency causes loss of hnf1ba expression within the DE progenitor compartment, therefore these cells are not competent to respond to Tfap2a activity (Naylor et al., 2013). These results suggest that tfap2a activates the DE program downstream of irx $3 b$.

Previous literature has determined Irx1 and Irx3 are dually required for Xenopus pronephros development (Reggiani et al., 2007; Alarcon et al., 2008). Importantly, loss of Irx1 in Xenopus results in proximal downregulation of the Nkcc2 expression domain, the slc12a1 equivalent in zebrafish (Reggiani et al., 2007). Therefore, we chose Iroquois homeobox family member, irx1a, as another important molecular player for analysis. In WT embryos, irx1a transcript expression was primarily localized to the DE segment (Fig. 6D) (Cheng et al., 2001). In trm mutants and tfap2a morphants, irx1a expression was nearly abrogated, with only a few remaining nephron cells expressing transcripts (Fig. 6D). When we induced overexpression of tfap2a at the $8 \mathrm{ss}$, the irx1a expression domain length was significantly expanded, indicating that tfap2a functions to activate irx1a expression directly or indirectly (Fig. 6E,F). Our results place tfap $2 a$ function with respect to irx activity, indicating that tfap2a functions downstream of irx $3 b$ and upstream of irx1a during distal segment differentiation. Taken together, our genetic analyses suggest a working model in which tfap2a coordinates a genetic regulatory network, likely through direct and indirect interactions, that controls the differentiation of distal nephron progenitors (Fig. 7). 


\section{Discussion}

Here, we have shown that tfap2a is required for distal nephron segment differentiation. We propose a model in which trm mutant cells progress through normal nephron developmental checkpoints until the final stage of differentiation (Fig. 7A). Our data supports the conclusion that tfap2a deficiency does not affect the derivation of the kidney lineage from intermediate mesoderm, as the expression of $h n f 1 b a$ and $c d h 17$ are unaffected. Further, we found that trm undergo nephron specification and epithelialization, as tfap2a-deficient cells exhibit segmental patterning, proper localization of polarity proteins, and form cilia. However, mutant cells appear to be frozen nonetheless in a specified renal precursor state, as they fail to turn on the suite of terminal differentiation genes that encode the distal solute transporters slc12a1, romk2, and clcnk. Taken together, we conclude that tfap2a is required for a discrete genetic circuit during terminal

Interestingly, this discovery disentangles the control of the solute transporter transcriptome from other differentiation processes, such as MET and polarity establishment in renal progenitors. Additionally, we have assembled a proposed Tfap2 genetic circuit that functions to achieve differentiation of distal nephron epithelium within the zebrafish embryonic kidney (Fig. 7B). In this network, tfap2a functions upstream of $t f a p 2 b$ as indicated by our genetic analyses. However, both tfap2a and tfap $2 b$ function synergistically in renal progenitors to turn on distal solute transporter genes, a level of redundancy that likely serves to amplify and reinforce this specific differentiation signal. This model is supported by the findings that elimination of $t f a p 2 a$ alleles led to defects in solute transporter expression, however elimination of $t f a p 2 b$ alleles alone had no consequence. Compound knockdown of tfap2a and tfap $2 b$ yielded the most severe phenotype, unveiling this layer of functional redundancy. As the trm mutation affects only one of the tfap2a spliceoforms, it is interesting that disrupting only this transcript results in a kidney phenotype, and suggests it encodes the sole protein variant that is fundamental for kidney development. The current study does not reconcile whether tfap2a and $t f a p 2 b$ are interacting by direct or indirect modes of regulation, and whether the suite of targets are direct or indirect (Fig. 7B). For example, it is possible tfap2a binds to the tfap $2 b$ promoter region functioning as a transcriptional activator. It is also feasible Tfap2a heterodimerizes with Tfap2b affecting the transcription of downstream target genes accordingly. These potential biochemical mechanisms are crucial areas for future investigation.

Further, our genetic model supports the conclusion that tfap2a acts in the same pathway as Iroquois homeobox genes irx3b and irx1a. Our genetic experiments indicate irx3b promotes tfap2a expression, and tfap2a functions upstream of irx1a (Fig. 7). These genes have been previously implicated as necessary for intermediate-distal early nephron development in zebrafish and frogs (Wingert and Davidson, 2011; Reggiani et al., 2007). Importantly, Iroquois factors likely play conserved roles in mammalian counterparts, as Irx3 and Irx1 define intermediate segment territories in developing S-shaped bodies (Reggiani et al., 
2007). Defining whether Irx3b directly regulates tfap2a, and if Tfap2a directly regulates irx1a, will also be important to discern in future studies as well.

Additionally, we discovered an intriguing phenotype when we globally overexpressed tfap2a, where s/c9a $3^{+}$proximal tubule and $s / c 12 a 3^{+}$distal late tubule cells ectopically coexpress s/c12a1, a marker of the DE tubule program (Fig. 5). This indicates that renal progenitors are competent to respond to Tfap2a, which is sufficient to activate the DE differentiation circuit. These mixed segment identities induced by tfap2a gain of function parallels a phenotype recently described as 'lineage infidelity,' which was observed in differentiating nephrons of Hox9,10,11-knockout mice (Magella et al., 2018; Drake et al., 2018). These studies similarly found individual cells that were dually expressing markers of more than one nephron segment. Specifically, in E18.5 Hoxa9,10,11/Hoxd9,10,11-deficient kidneys, cells were scattered throughout $\mathrm{Hnf}_{4} \mathrm{a}^{+}$proximal tubules co-expressing collecting duct markers DBA and Krt8. Strikingly, mutant kidneys sometimes possessed entire Slc12a $1^{+}$ascending loop of Henle (the DE analog in zebrafish) domains that co-labeled with Krt8. These developing mutant nephrons undergo a normal segment specification phase (E15.5), but later fail to maintain appropriate differentiation programs. It is an interesting prospect that Hox mutants exhibit a normal specification phase, as our data similarly suggests that tfap2a is dispensable for nephron patterning, but necessary for inducing a proper differentiation state. During zebrafish neural crest development, tfap2a promotes expression of Hox group 2 genes to form segments of the pharyngeal skeleton (Knight et al., 2003; Barrallo-Gimeno et al., 2003). Collectively, these studies warrant Hox genes as important future areas of study regarding the Tfap2 genetic regulatory network controlling nephron differentiation.

With the advent of next-generation sequencing technologies, recent work in the field has identified new targets within the Tfap2 genetic regulatory network (Seberg et al., 2017). To do this, microarray analyses and ChIP-seq were employed in tandem to identify novel players regulating melanocyte development within the Tfap2a GRN. To collect candidates, microarray analysis of tfap $2 a^{-/}$zebrafish trunks and tfap2adeficient mouse melanocyte lines were conducted. Microarray results were compared to ChIP-Seq data gathered from mouse and human melanocytes to determine which differentially regulated genes were direct transcriptional targets of Tfap2a. The findings suggested Tfap2a directly regulates effectors of melanocyte terminal differentiation (e.g. dct, mlpha, mc2r, sox10, mitf). Conducting microarray analysis of our trm mutant zebrafish embryos and overlapping this data with the previously published mammalian kidney Tfap2a Chip-Seq data set (Pihlajamaa et al., 2014) will help to identify putative direct targets governing terminal differentiation of distal nephron cells.

A separate study performed RNA-sequencing analysis on dissected mandibular processes from double conditional Tfap2a/Tfap2b mouse mutant embryos to find Tfap2a/2b target genes during branchial arch patterning (Van Otterloo et al., 2018). Upon evaluating differentially expressed genes by Geneset 
enrichment analyses (GSEAs) 'homeobox transcription factors' was identified as the number one overrepresented cluster. Further genetic workup of DIx, Msx, and Emx homeobox gene families established these factors as major network targets under the control of Tfap2a/b during branchial arch development. Performing RNA-profiling and GSEAs of tfap2a-deficient developing nephrons would aid in pinpointing molecular pathways for future workup. The majority of differentially expressed genes in Tfap $2 a / 2 b$ murine branchial arches were associated with regions corresponding to poised histone marks, supporting a direct mode of regulation (Van Otterloo et al., 2018). However, it remains a possibility that tfap2a regulates transcription in nephron precusors via an intermediate factor or chromatin modifier as part of the GRN. In further support of an indirect mode of regulation, Tfap2a acts as a tissue-specific pioneer factor in the epididymis to modify chromatin structure activating androgen receptor signaling (Pihlajamaa et al., 2014). We speculate that Tfap2a/b operates both directly and indirectly to regulate expression of GRN components responsible for terminal differentiation of distal nephron tubules. To entertain this prospect, ATAC-seq and ChIP-seq methods could be installed in the future to determine differential chromatin accessibility in tfap2a-deficient renal progenitors.

Tfap2a has roles in induction, early specification, patterning, cell survival, and differentiation depending on the tissue type (Eckert et al., 2005). In neural crest, tfap2a plays dual roles in early development and later differentiation events. tfap2a and foxd3 establish proper Bmp and Wnt signaling, which is required for early neural crest induction (de Croze et al., 2011; Bhat et al., 2012). In tfap2a-deficiency, migratory neural crest cells undergo increased apoptosis, indicating tfap2a is necessary for survival. It is speculated that because these cells cannot differentiate properly, they undergo apoptosis (Knight et al., 2003). Further, tfap2a is required for the specification and differentiation of inner ear neurons (Kantarci et al., 2015). tfap2a is also a necessary element for establishing preplacodal ectoderm competence and specification of ectoderm lineages (Bhat et al., 2012; Kwon et al., 2010). The concerted action of tfap2a and phox2a promote the differentiation of noradrenergic neurons in the central nervous system (Holzschuh et al., 2003). tfap2a also stimulates pathways that promote melanocyte terminal differentiation and survival (Van Otterloo et al., 2010; Seberg et al., 2017). tfap2a and tfap $2 b$ are required for the survival of sympathetic progenitors and differentiated sympathetic neurons (Schmidt et al., 2011). Differentiation of amacrine cells during retinogenesis is also induced by tfap2a and tfap2b (Bassett et al., 2012; Jin et al., 2015), and they function redundantly and non-autonomously to regulate cartilage patterning by modulating Fgf signals in the pharyngeal ectoderm (Knight et al., 2005). Interestingly, in the developing mouse kidney, Tfap2b is required for the maintenance and survival of renal epithelium (Moser et al., 1997). In Tfap2b null mice, distal tubules and collecting duct cells undergo a massive wave of apoptosis. Additionally, histology revealed mutant kidneys possess numerous cysts in the distal tubules and collecting ducts. Anti-apoptotic genes $b c l-X_{L}, b c l-w$, and $b c / 2$ are strongly downregulated, supporting the idea that Tfap $2 b$ programs cell survival during embryogenesis. However, in our trm mutant, we are confident cell death does not contribute to the decreased solute transporter expression observed. Upon acridine orange analysis, we 
saw no obvious increase in the number of dying cells. Further, we observe no gaps in the nephron tubule as a result of dying cells, as indicated by continuous expression of cdh17 expression at 24 hpf or at later time points. Our data strongly suggests that the main function of tfap $2 a$ and tfap $2 b$ during nephron development is not specification, patterning, or survival, but rather to promote terminal differentiation of distal nephron epithelium.

Based on recent studies in the zebrafish model, upstream candidates for regulating tfap2a and tfap $2 b$ may occupy the prostaglandin signaling pathway, which is essential to control the balance of DE and DL territories during zebrafish nephrogenesis (Poureetezadi et al., 2016), or include transcription factors like mecom, tbx2a/2b, or emx1 that regulate DL development (Li et al., 2014; Drummond et al., 2016; Morales et al., 2018). Additional network candidates which may crosstalk with tfap2a/2b include sall1 and sox11. In mammals Sall1 has been found to be a critical factor in the development of the thick ascending limb (TAL), which is the segment analogous to the zebrafish DE region (Basta et al., 2017). Sall1 mutants exhibited significantly decreased expression of Kcnj1 (Romk2), Slc12a1, Irx2, and Pou3f3, among other major loop of Henle and distal lineage genes. Immunohistochemistry analysis revealed a near total loss of S/c12a $1^{+}$ loop of Henle structures in the inner medulla of mutant embryos. In the murine kidney, Sox11 is also necessary for proper loop of Henle ontogeny (Neirijnck et al., 2018). Sox11-deficient kidneys have significantly reduced expression of Slc12a1, Irx1, and Irx2. Sall1 and Sox11 are excellent candidates to situate in the Tfap2a GRN, due to their involvement in the DE/TAL segment development. Additionally, Sall1, Sox11, and tfap2a mutations all reduce Irx gene expression, suggesting they may act in the same pathway.

Knowledge about the terminal differentiation programs of each nephron segment has central importance for understanding kidney disease and to advance regenerative medicine. Human BOFS is associated with the occurrence of dysplastic kidneys, but the underlying mechanisms are not known. Our zebrafish trm mutant provides an opportunity to model aspects of BOFS at the molecular level of the nephron. With regard to kidney engineering, current groups face major challenges of generating mature, differentiated nephron structures in kidney organoid cultures (Hariharan et al., 2015; Chambers et al., 2016; Oxburgh et al., 2017; Takasato et al., 2017). However, growing mouse and particularly human kidney organoids is an immensely promising technology to study kidney development, model renal disease, and perform nephrotoxicity assays (Morizane and Bonventre, 2017). Reconstructing the mammalian nephron requires understanding the correct signals to guide stem cells down the appropriate differentiation paths to generate highly specialized compartments of cells. While terminally differentiated nephrons have yet to be achieved in organoid cultures, the discovery of terminal differentiation factors, like tfap2a and tfap2b, can herald progress in this crucial aspect of the kidney organoid field. In sum, our work indicates that further elucidation of the Tfap2a/TFAP2A gene regulatory network in zebrafish, murine, and human nephron progenitors can shed valuable insights into nephron differentiation and congenital renal disease. 


\section{Materials and Methods}

\section{Ethics statement and zebrafish husbandry}

Adult zebrafish were maintained in the Center for Zebrafish Research at the University of Notre Dame Freimann Life Science Center. All studies were performed and supervised with by the University of Notre Dame Institutional Animal Care and Use Committee (IACUC), under protocol numbers 13-021 and 16-025. Tübingen strain animals were used for WT experiments. Zebrafish embryos were raised in E3 embryo media, staged, and fixed as described (Kimmel et al., 1995).

\section{Whole mount and fluorescent in situ hybridization (WISH, FISH)}

WISH and FISH were performed as described (Marra et al., 2017; Brend and Holley, 2009; Lengerke et al., 2011; Cheng et al., 2014) with antisense RNA probes. Probes were synthesized using IMAGE clone template plasmids for in vitro transcription (Wingert et al., 2007; Wingert and Davidson, 2011). Digoxigenin-labeled probes consist of: wt1b, slc20a1a, slc12a1, dlx2a, romk2, tfap2a, tfap2b, clcnk, slc12a3, slc9a3, cdh17, hnf1ba, irx3b, irx1a, trpm7, and stc1. Fluorescein-labeled probes consist of: tfap2b, slc12a1, slc12a3, tfap2a. For all gene expression studies, each analysis was performed in triplicate with sample size of at least $n=20$ for each replicate. Representative animals were imaged and absolute length measurements were collected.

\section{Whole mount immunofluorescence (IF)}

Whole mount IF studies were completed as described (McCampbell et al., 2015). To assess Tfap2a protein expression, anti-tfap2a (1:50) (LifeSpan Biosciences) and anti-goat secondary antibody were used. To analyze proliferation, anti-phospho-Histone H3 (1:200) (Millipore), and anti-rabbit secondary antibody (Alexa Fluor, Invitrogen) were used (Kroeger et al., 2017). For cilia studies, anti-acetylated a-tubulin (1:400) and anti-mouse secondary antibody (Alexa Fluor, Invitrogen) were used (Marra et al., 2017). Monoclonal a6F anti-NaKATPase (1:35) (Developmental Studies Hybridoma Bank) and anti-aPKC (1:250) (Santa-Cruz) were applied to embryos incubated in $0.003 \%$ PTU to prevent pigmentation and fixed in Dent's solution ( $80 \%$ methanol, 20\% DMSO) overnight at $4{ }^{\circ} \mathrm{C}$ (Gerlach and Wingert, 2014). Anti-mouse and anti-rabbit secondary antibodies (Alexa Fluor, Invitrogen) were used respectively. All fluorescentlyconjugated secondary antibodies were applied at a 1:500 dilution, and 4,6-diamidino-2-phenylindole dihydrochloride (DAPI) (Invitrogen) was used to stain nuclei.

\section{Image acquisition and statistical analysis}

A Nikon Eclipse $\mathrm{Ni}$ with DS-Fi2 camera was used to image WISH samples. A Nikon C2 confocal microscope was used to image whole mount FISH and IF samples. The polyline tool in Nikon Elements imaging software was used to measure gene expression domains. A minimum of 3 representative samples 
for each control and experimental group were imaged and measured. Averages and standard errors were calculated. Unpaired t-tests or one-way ANOVA tests were completed for statistical analyses.

\section{Mutagenesis, whole genome sequencing and genotyping}

WT zebrafish were exposed to ethylnitrosurea and haploids generated as described (Kroeger et al., 2014). Whole genome sequencing was performed as described (Leshchiner et al., 2012). Pools of 20 trm mutants and 20 WT siblings were identified by WISH analysis for slc12a1 (DE) expression. DNA isolation was conducted using the DNAeasy blood and tissue kit (Qiagen). WGS results were interpreted by SNPtrack software (Leshchiner et al., 2012; Ryan et al., 2013). Isolation of genomic DNA from individual trm animals was performed and PCR amplification of the tfap2a locus was completed using the following primers: forward

TTTGAACGCTGGCCACCGCCACCTCGCCCTACAATTATTGTTGGCTTGATTTAATTTGCACGTTCGTTT TTGATTTGTCCTTCTGAATTTCACGTCTTTT-3' reverse CTCACATGAAGAAAATCTTTGTAATAGCCTT-3'. For all studies, trm mutants were confirmed by genotyping and/or abrogated $d / x 2$ expression. The QIAquick PCR Purification Kit was used to purify PCR product and sequenced with the forward primer by the University of Notre Dame Genomics Core Facility. Genotyping of $h$ s:tfap2a transgenic ( $T g(h s p 70: t f a p 2 a)^{x 24}$, which was a generous gift from Bruce Riley, was conducted by performing PCR amplification (34 cyles, $60^{\circ} \mathrm{C}$ annealing) of the transgene and running product on a $1 \%$ agarose gel. The following primers were used: forward 5'-CTCCTCTCAATGACAGCTG-3' reverse 5'-ATGGCGGTTGGAAGTCTGAA-3'.

\section{Overexpression experiments}

To activate the heat-shock inducible tfap2a transgene, heterozygous transgenic embryos were incubated at $38^{\circ} \mathrm{C}$ for 30 minutes as described (Bhat et al., 2012; Kantarci et al., 2015). For rescue and gain-offunction studies, transgenic embryos were heat shocked at the 8ss. For FISH gain-of-function studies, transgenic embryos were heat shocked at the 10ss. For cRNA synthesis, the open reading frame of tfap2a was subcloned into the pCS2 vector. The primers used for subcloning were: forward 5'GATCATCGATGCCGCCACCATGTTAGTGCACAGTTTTTCCGCGATGGATC-3' reverse 5'GATCTCTAGATCACTTTCTGTGCTTCTCATCTTTGTCACC-3'. For in vitro transcription, tfap2a template was linearized using Not1 restriction enzyme. Runoff reactions were performed using the mMessage mMachine Sp6 kit (Ambion). 50 picograms (pg) of tfap2a cRNA were injected into 1 cell stage embryos.

\section{Morpholino knockdown and RT-PCR}

All morpholino oligonucleotides were synthesized by Gene Tools, LLC. tfap2a MO-splice (tfap2a MO4) targets the exon 2 - intron 2 splice site: 5'-AGCTTTTCTTCTTACCTGAACATCT-3' [36]. tfap2b MO-splice (tfap2b MO1) targets the exon 4 - intron 4 splice site: 5'-GCCATTTTTCGACTTCGCTCTGATC-3' (Knight 
617

618

619

620

621

622

623

624

625

626

627

628

629

630

631

632

633

634

635

636

637

638

639

640

641

642

643

644

645

646

647

648

649

650

651

652

et al., 2005). irx3b MO-ATG (irx3b MO2) targets the start site: 5'-ATAGCCTAGCTGCGGGAGAGACATG3'. Morpholinos were solubilized in DNase/RNase free water to create $4 \mathrm{mM}$ stock solutions and stored at $20^{\circ} \mathrm{C}$. The stocks were diluted as follows for microinjection: tfap2a-MO 1:12, tfap2b-MO 1:10, irx3b MO 1:10. 1-cell stage embyros were injected with approximately $3 \mathrm{nl}$ of morpholino. All splice-blocking MOs were verified by RT-PCR. Transcript analysis of tfap2a and tfap $2 b$ splicing in WT, WT sibs, trm mutants, tfap2a morphants, and tfap2b morphants was performed using RT-PCR (Galloway et al., 2008). In brief, RNA was isolated from pools of about 20 embryos, cDNA was synthesized using random hexamers (Superscript IV, Invitrogen), and PCR was performed with the following primers. trm mutant transcript analysis: forward 5'-GCATTGCATCTAA-AGGGCAGACGAA-3' 5'TAAGGGTCCTGAGACTGCGGATAGA- 3'. tfap2a MO-splice transcript analysis: forward 5'CCCTATCCATGGAATACCTCACTC-3' reverse 5'-GATTACA-GTTTGGTCTGGGATGTGA-3'. tfap2b MOsplice transcript analysis: forward 5'-AGTGC-CTGAACGCGTCTCTGCTTGGT-3' reverse 5'TGACATTCGCTGCCTTGCGTCTCC-3'. For tfap2a MO and tfap2b MO transcript analysis, bands were gel-extracted, purified, and sequenced. For trm mutant transcript analysis, bands were gel-extracted, purified, and cloned into the pGemTEasy vector (Promega), and minipreps were sequenced.

\section{Alcian blue staining and o-dianisidine staining}

Alcian blue cartilage staining was performed as previously described (Neuhauss et al., 1996). In brief, larvae were fixed at $4 \mathrm{dpf}$ for 2 hours at RT in 4\% PFA. Larvae were bleached for 1 hour in $10 \% \mathrm{KOH}, 30 \%$ $\mathrm{H}_{2} \mathrm{O}_{2}, 20 \%$ Tween diluted in distilled water. Samples were digested with proteinase $\mathrm{K}(10 \mathrm{mg} / \mathrm{mL})$ diluted to $1 \mathrm{X}$ for 20 minutes. Samples were stained in 0.1\% Alcian Blue (Sigma) dissolved in 70\% ethanol / 5\% concentrated $\mathrm{HCl}$ overnight, shaking at RT in glass vials. Larvae were destained using acidic ethanol for 4 hours, dehydrated by an ethanol series, and stored in glycerol. O-Dianisidine staining was performed as described on $4 \mathrm{dpf}$ larvae to visualize blood and vasculature (Wingert et al., 2004).

\section{Acridine orange assay}

Acridine orange (AO; Sigma A6014; $100 \mathrm{X}$ ) staining was performed on WT and trm mutants to analyze cell death (Kroeger et al., 2017; Westerfield, 193). In brief, a 50 X AO stock solution (250 $\mu \mathrm{g} / \mathrm{ml}$ ) was made. At $24 \mathrm{hpf}$, embryos were incubated in 1:50 AO solution (made from $50 \mathrm{X}$ stock) diluted in 0.003\% PTU/E3 media protected from light for 1 hour. Embryos were then washed three times with $0.003 \%$ PTU/E3, and then imaged with a dissecting microscope under the GFP filter in $2 \%$ methylcellulose $/ 0.02 \%$ tricaine.

\section{Dextran clearance assay}

To assess kidney function in WT and trm mutants, clearance assays using fluorescent $40 \mathrm{kDa}$ dextranfluorescein (FITC) (Invitrogen) were completed. Embryos were treated with $0.003 \%$ PTU at 24 hpf. At 2 dpf, embryos were anesthetized with $0.02 \%$ tricaine and dextran-FITC was injected into circulation. Live 
bioRxiv preprint doi: https://doi.org/10.1101/460105; this version posted November 2, 2018. The copyright holder for this preprint (which was not certified by peer review) is the author/funder, who has granted bioRxiv a license to display the preprint in perpetuity. It is made available under aCC-BY-NC 4.0 International license.

653

654

fluorescent imaging was performed 1 hour after injection and 24 hours after injection. Embryos were liveimaged with a dissecting microscope under the GFP filter in methylcellulose/0.02\% tricaine. 


\section{Acknowledgements}

We thank Bruce Riley for sharing the inducible hs:tfap2a zebrafish transgenic with us. We thank the staffs of the Department of Biological Sciences and the Center for Zebrafish Research at the University of Notre Dame for their dedication and care of our zebrafish aquarium. Finally, we thank the members of our lab for their support, discussions, and insights about this work.

\section{Competing Interests}

The authors declare no competing interests.

\section{Funding}

This work was supported by the National Institutes of Health [R01DK100237 to R.A.W.]. We are grateful to Elizabeth and Michael Gallagher for a generous gift to the University of Notre Dame on behalf of their family for the support of stem cell research. The funders had no role in the study design, data collection and analysis, decision to publish, or manuscript preparation.

\section{Author Contributions}

BEC, GFG, KHC, EGC, IL and RAW performed experiments. BEC, GFG, KHC, EGC, WG and RAW analyzed the results. BEC and RAW wrote and revised the paper.

\section{Data Availability}

All data related to the present study is provided within the figures and supplementary information. 


\title{
References
}

\begin{abstract}
Alarcón, P., Rodríguez-Seguel, E., Fernández-González, A., Rubio, R., and Gómez-Skarmeta, J.L. (2008). A dual requirement for Iroquois genes during Xenopus kidney development. Development 135, 3197-3207.
\end{abstract}

Airik, R., and Kispert, A. (2007). Down the tube of obstructive nephropathies: the importance of tissue interactions during ureter development. Kidney Int. 72, 1459-1467.

Barrallo-Gimeno, A., Holzschuh, J., Driever, W., and Knapik, E.W. (2003). Neural crest survival and differentiation in zebrafish depends on mont blanc/tfap2a gene function. Development 131, 1463-1477.

Bassett, E.A., Korol, A., Deschamps, P.A., Buettner, R., Wallace, V.A., Williams, T., and West-Mays J.A. (2012). Overlapping expression patterns and redundant roles for AP-2 transcription factors in the developing mammalian retina. Dev. Dyn. 241, 814-829.

Basta, J. M., Robbins L., Denner D. R., Kolar, G. R., and Rauchman, M. A. (2017). Sall1-NuRD interaction regulates multipotent nephron progenitors and is required for loop of Henle formation. Development 144, 3080-3094.

Bhat, N., Kwon, H.J., and Riley, B.B. (2012). A gene network that coordinates preplacodal competence and neural crest specification in zebrafish. Dev. Biol. 373,107-117.

Brend, T., and Holley, S.A. (2009). Zebrafish whole mount high-resolution double fluorescent in situ hybridization. J. Vis. Exp. 25, pii1229.

Brewer, S., and Williams, T. (2004a) Loss of AP-2alpha impacts multiple aspects of ventral body wall development and closure. Dev. Biol. 267, 399-417.

Brewer, S., Feng, W., Huang, J., Sullivan, S., and Williams, T. (2004b) Wnt1-Cre-mediated deletion of AP-2alpha causes multiple neural crest-related defects. Dev. Biol. 267, 135-52.

Chambers, J., McKee, R.A., Drummond, B.E., and Wingert R.A. (2016). Evolving technology: creating kidney organoids from stem cells. AIMS Bioeng. 3, 305-318.

Cheng, C.W., Hui, C., Strähle, U., and Cheng, S.H. (2001). Identification and expression of zebrafish Iroquois homeobox gene irx1. Dev. Genes. Evol. 211, 442-444.

Cheng, C.N., Li, Y., Marra, A.N., Verdun, V., and Wingert, R.A. (2014). Flat mount preparation for observation and analysis of zebrafish embryo specimens stained by whole mount in situ hybridization. $J$. Vis. Exp. 89, e51604.

Cheng, C.N., and Wingert, R.A. (2015). Nephron proximal tubule patterning and corpuscles of Stannius formation are regulated by the sim1a transcription factor and retinoic acid in zebrafish. Dev. Biol. 399, 100116.

Chung, E., Deacon, P., and Park, J.S. (2017). Notch is required for the formation of all nephron segments and primes nephron progenitors for differentiation. Development 144, 4530-4539.

de Crozé, N,, Maczkowiak, F., and Monsoro-Burq, A.H. (2011). Reiterative AP2a activity controls sequential steps in the neural crest gene regulatory network. Proc. Natl. Acad. Sci. USA 108, 155-60.

Desgrange, A., and Cereghini, S. (2015). Nephron patterning: lessons from Xenopus, zebrafish and mouse studies. Cells 4, 483-499. 
Drake, K.A., Adam, M., Mahoney, R., and Potter, S.S. (2018). Disruption of Hox9,10,11 function results in cellular level lineage infidelity in the kidney. Sci. Rep. 8, 6306.

Dressler, G. R. (2006). The cellular basis of kidney development. Annu. Rev. Cell Dev. Biol. 22, 509-529.

Drummond, B.E., Li, Y., Marra, A.N., Cheng, C.N., and Wingert, R.A. (2016). The tbx2a/b transcription factors direct pronephros segmentation and corpuscle of Stannius formation in zebrafish. Dev. Biol. 421, 52-66.

Eckert, D., Buhl, S., Weber, S., Jäger, R., and Schorle, H. (2005). The AP-2 family of transcription factors. Genome Biol. 6, 246.

Galloway, J.L., Wingert, R.A., Thisse, C., Thisse, B., and Zon, L.I. (2008). Combinatorial regulation of novel erythroid gene expression in zebrafish. Exp. Hematol. 36, 424-432.

Gerlach, G.F., and Wingert, R.A. (2013) Kidney organogenesis in the zebrafish: insights into vertebrate nephrogenesis and regeneration. Wiley Interdiscip. Rev. Dev. Biol. 2, 559-585.

Gerlach, G.F., and Wingert, R.A. (2014). Zebrafish pronephros tubulogenesis and epithelial identity maintenance are reliant on the polarity proteins Prkc iota and zeta. Dev. Biol. 396,183-200.

Greco, D., Zellmer, E., Zhang, Z., and Lewis, E. (1995). Transcription factor AP-2 regulates expression of the dopamine beta-hydroxylase gene. J. Neurochem. 65, 510-516.

Green, R.M., Feng, W., Phang, T., Fish, J.L., Li, H., Spritz, R.A., Marcucio, R.S., Hooper, J., Jamniczky, H., Hallgrímsson, B., et al. (2014). Tfap2a-dependent changes in mouse facial morphology result in clefting that can be ameliorated by a reduction in Fgf8 gene dosage. Dis. Model Mech. 8, 31-43.

Handwerger, S. (2009). New insights into the regulation of human cytotrophoblast cell differentiation. Mol. Cell Endocrinol. 323, 94-104.

Hariharan, K., Kurtz, A., and Schmidt-Ott, K.M. (2015). Assembling kidney tissues from cells: the long road from organoids to organs. Front. Cell Dev. Biol. 3, 70.

Hilger-Eversheim, K., Moser, M., Schorle, H., and Buettner, R. (2000). Regulatory roles of AP-2 transcription factors in vertebrate development, apoptosis and cell-cycle control. Gene 260,1-12.

Hoffman, T.L., Javier, A.L., Campeau, S.A., Knight, R.D., and Schilling, T.F. (2007). Tfap2 transcription factors in zebrafish neural crest development and ectodermal evolution. J. Exp. Zool. B Mol. Dev. Evol. 308, 679-691.

Holzschuh, J., Barrallo-Gimeno, A., Ettl, A.K., Durr, K., Knapik, E.W., Driever, W. (2003). Noradrenergic neurons in the zebrafish hindbrain are induced by retinoic acid and require tfap2a for expression of the neurotransmitter phenotype. Development 130, 5741-5754.

Jin, K., Jiang, H., Xiao, D., Zou, M., Zhu, J., and Xiang, M. (2015). Tfap2a and 2b act downstream of Ptf1a to promote amacrine cell differentiation during retinogenesis. Mol. Brain. 8, 28.

Kantarci, H., Edlund, R.K., Groves, A.K., and Riley B.B. (2015). Tfap2a promotes specification and maturation of neurons in the inner ear through modulation of Bmp, Fgf and notch signaling. PLoS Genet. 11, e1005037.

Kerber, B., Monge, I., Mueller, M., Mitchell, P.J., and Cohen, S.M. (2001). The AP-2 transcription factor is required for joint formation and cell survival in Drosophila leg development. Development 128, 1231-8. 
Kim, H.S., Hong, S.J., LeDoux, M.S., and Kim, K.S. (2001). Regulation of the tyrosine hydroxylase and dopamine beta-hydroxylase genes by the transcription factor AP-2. J. Neurochem. 76, 280-294.

Kimmel, C.B., Ballard, W.W., Kimmel, S.R., Ullmann, B., and Schilling, T.F. (1995). Stages of embryonic development of the zebrafish. Dev. Dyn. 203, 253-310.

Knight, R.D., Nair, S., Nelson, S.S., Afshar, A., Javidan, Y., Geisler, R., Rauch, G.J., and Schilling, T.F. (2003). lockjaw encodes a zebrafish tfap2a required for early neural crest development. Development $130,5755-68$.

Knight, R.D., Javidan, Y., Zhang, T., Nelson, S., and Schilling, T.F. (2005). AP2-dependent signals from the ectoderm regulate craniofacial development in the zebrafish embryo. Development 132, 31273138.

Kroeger, P.T. Jr., Poureetezadi, S.J., McKee, R., Jou, J., Miceli, R., and Wingert, R.A. (2014). Production of haploid zebrafish embryos by in vitro fertilization. J. Vis. Exp. 89, e51708.

Kroeger, P.T. Jr., Drummond, B.E., Miceli, R., McKernan, M., Gerlach, G.F., Marra, A.N., Fox, A., McCampbell, K.K., Leshchiner, I., Rodriguez-Mari, A., BreMiller, R., et al. (2017). The zebrafish kidney mutant zeppelin reveals that brca2/fancd1 is essential for pronephros development. Dev. Biol. 428,148163.

Kwon, H.J., Bhat, N., Sweet, E.M., Cornell, R.A., and Riley, B.B. (2010). Identification of early requirements for preplacodal ectoderm and sensory organ development. PLoS Genet. 6, e1001133.

Lengerke, C., Wingert, R., Beeretz, M., Grauer, M., Schmidt, A.G., Konantz, M., Daley, G.Q., and Davidson, A.J. (2011). Interactions between $\mathrm{Cdx}$ genes and retinoic acid modulate early cardiogenesis. Dev. Biol. 163,134-142.

Leshchiner, I., Alexa, K., Kelsey, P., Adzhubei, I., Austin-Tse, C.A., Cooney, J.D., Anderson, H., King, M.J., Stottmann, R.W., Garnaas, M.K., et al. (2012). Mutation mapping and identification by wholegenome sequencing. Genome Res. 22, 1541-1548.

Li, Y., Cheng, C.N., Verdun, V.A., and Wingert, R.A. (2014). Zebrafish nephrogenesis is regulated by interactions between retinoic acid, mecom, and Notch signaling. Dev. Biol. 386, 111-122.

Li, W., and Cornell, R.A. (2007). Redundant activities of Tfap2a and Tfap2c are required for neural crest induction and development of other non-neural ectoderm derivatives in zebrafish embryos. Dev. Biol. 304, 338-54.

Lindström, N.O., Lawrence, M.L., Burn, S.F., Johansson, J.A., Bakker, E.R.M., Ridgway, R.A., Chang, C.H., Karolak, M.J., Oxburgh, L., Headon, D.J., et al. (2015). Integrated B-Catenin, BMP, PTEN, and Notch signalling patterns the nephron. Elife 3, e04000.

Lindström, N.O., McMahon, J.A., Guo, J., Tran, T., Guo, Q., Rutledge, E., Parvez, R.K., Saribekyan, G., Schuler, R.E., Liao, C., et al. (2018a). Conserved and divergent features of human and mouse kidney organogenesis. J. Am. Soc. Nephrol. 29, 785-805.

Lindström, N.O., De Sena Brandine, G., Tran, T., Ransick, A., Suh, G., Guo, J., Kim, A.D., Parvez, R.K., Ruffins, S.W., Rutledge, E.A., et al. (2018b). Progressive recruitment of mesenchymal progenitors reveals a time-dependent process of cell fate acquisition in mouse and human nephrogenesis. Dev. Cell. 45, 651-660. 
Magella, B., Mahoney, R., Adam, M., and Potter, S.S. (2018). Reduced Abd-B Hox function during kidney development results in lineage infidelity. Dev. Biol. 438, 84-93.

Marra, A.N., and Wingert, R.A. (2014). Roles of Iroquois transcription factors in kidney development. Cell Dev. Biol. 3, 1000131.

Marra, A.N., and Wingert, R.A. (2016). Epithelial cell fate in the nephron tubule is mediated by the ETS transcription factors etv5a and etv4 during zebrafish kidney development. Dev. Biol. 411, 231-245.

Marra, A.N., Li, Y., and Wingert, R.A. (2016). Antennas of organ morphogenesis: the roles of cilia in vertebrate kidney development. Genesis 54, 457-469.

Marra, A.N., Ulrich, M., White, A., Springer, M., and Wingert, R.A. (2017). Visualizing multiciliated cells in the zebrafish through a combined protocol of whole mount fluorescent in situ hybridization and immunofluorescence. J. Vis. Exp. 129, e56261.

McCampbell, K.K., Springer, K.N., and Wingert, R.A. (2015). Atlas of cellular dynamics during zebrafish adult kidney regeneration. Stem Cells Int. 2015, 547636.

McKee, R., Gerlach, G.F., Jou, J., Cheng, C.N., and Wingert, R.A. (2014). Temporal and spatial expression of tight junction genes during zebrafish pronephros development. Gene Expr. Patterns 16, 104113.

Milunsky, J.M., Maher, T.A., Zhao, G., Roberts, A.E., Stalker, H.J., Zori, R.T., Burch, M.N., Clemens, M., Mulliken, J.B., Smith, R., et al. (2008). TFAP2A mutations result in branchio-oculo-facial syndrome. Am. J. Hum. Genet. 82,1171-1177.

Morales, E.M., Handa, N., Drummond, B.E., Chambers, J.M., Marra, A.N., Addiego, A., and Wingert, R.A. (2018). Homeogene emx1 is required for nephron distal segment development in zebrafish. Sci. Reports in press.

Moser, M., Rüschoff, J., and Buettner, R. (1997a). Comparative analysis of AP-2 alpha and AP-2 beta gene expression during murine embryogenesis. Dev. Dyn. 208, 115-24.

Moser, M., Pscherer, A., Roth, C., Becker, J., Mücher, G., Zerres, K., Dixkens, C., Weis, J., GuayWoodford, L., Buettner R., et al. (1997b). Enhanced apoptotic cell death of renal epithelial cells in mice lacking transcription factor AP-2beta. Genes Dev.11, 1938-48.

Naylor, R.W., Przepiorski, A., Ren, Q., Yu, J., and Davidson, A.J. (2013). HNF1 $\beta$ is essential for nephron segmentation during nephrogenesis. J. Am. Soc. Nephrol. 24, 77-87.

Naylor, R.W., Qubisi, S.S., and Davidson, A.J. (2017). Zebrafish pronephros development. Results Probl. Cell Differ. 60, 27-53.

Neirijnck, Y., Reginensi, A., Renkema, K.Y., Massa, F., Kozlov, V.M., Dhib, H., Bongers, E.M.H.F., Feitz, W.F., van Eerde, A.M., Lefebvre, V., et al. (2018). Sox11 gene disruption causes congenital anomalies of the kidney and urinary tract (CAKUT). Kidney Int. 93, 1142-1153.

Neuhauss, S.C., Solnica-Krezel, L., Schier, A.F., Zwartkruis, F., Stemple, D.L., Malicki, J., Abdelilah, S., Stainier, D.Y., and Driever W. (1996). Mutations affecting craniofacial development in zebrafish. Development 123, 357-67.

O'Brien, E.K., d'Alençon, C., Bonde, G., Li, W., Schoenebeck, J., Allende, M.L., Gelb, B.D., Yelon, D., Eisen, J.S., and Cornell, R.A. (2004). Transcription factor Ap-2alpha is necessary for development of 
901

902

903

904

905

906

907

908

909

910

911

912

913

914

915

916

917

918

919

920

921

922

923

924

925

926

927

928

929

930

931

932

933

934

935

936

937

938

939

940

941

942

943

944

945

946

947

948

949

950

951

952

953

954

955

embryonic melanophores, autonomic neurons and pharyngeal skeleton in zebrafish. Dev. Biol. 265, 246261.

Oxburgh, L., Carroll, T.J., Cleaver, O., Gossett, D.R., Hoshizaki, D.K., Hubbell, J.A., Humphreys, B.D., Jain, S., Jensen, J., Kaplan, D.L., et al. (2017). (Re)Building a Kidney. J. Am. Soc. Nephrol. 28, 1370-1378.

Pfisterer, P., Ehlermann, J., Hegen, M., and Schorle, H. (2001). A subtractive gene expression screen suggests a role of transcription factor AP-2 alpha in control of proliferation and differentiation. J. Biol. Chem. 277, 6637-44.

Pihlajamaa, P., Sahu, B., Lyly, L., Aittomäki, V., Hautaniemi, S., and Jänne, O.A. (2014). Tissuespecific pioneer factors associate with androgen receptor cistromes and transcription programs. EMBO J. 33, 312-26.

Poureetezadi, S.J., Cheng, C.N., Chambers, J.M., Drummond, B.E., and Wingert, R.A. (2016). Prostaglandin signaling regulates nephron segment patterning of renal progenitors during zebrafish kidney development. Elife 5, pii:e17551.

Poureetezadi, S.J., and Wingert, R.A. (2016) Little fish, big catch: zebrafish as a model for kidney disease. Kidney Int. 89, 1204-1210.

Reggiani, L., Raciti, D., Airik, R., Kispert, A., and Brändli, A.W. (2007). The prepattern transcription factor Irx3 directs nephron segment identity. Genes Dev. 21, 2358-2370.

Ryan, S., Willer, J., Marjoram, L., Bagwell, J., Mankiewicz, J., Leshchiner, I., Goessling, W., Bagnat, M., and Katsanis, N. (2013). Rapid identification of kidney cyst mutations by whole exome sequencing in zebrafish. Development 140, 4445-4451.

Satoda, M., Zhao, F., Diaz, G.A., Burn, J., Goodship, J., Davidson, H.R., Pierpont, M.E., and Gelb B.D. (2000). Mutations in TFAP2B cause Char syndrome, a familial form of patent ductus arteriosus. Nat. Genet. 25, 42-6.

Saxen, L. (1987). Organogenesis of the kidney. Cambridge, UK: Cambridge University Press.

SchedI, A. (2007). Renal abnormalities and their developmental origin. Nat. Rev. Genet. 8, 791-802.

Schmidt, M., Huber, L., Majdazari, A., Schütz, G., Williams, T., and Rohrer H. (2011). The transcription factors $A P-2 \beta$ and $A P-2 \alpha$ are required for survival of sympathetic progenitors and differentiated sympathetic neurons. Dev. Biol. 355, 89-100.

Schorle, H., Meier, P., Buchert, M., Jaenisch, R., and Mitchell, P.J. (1996). Transcription factor AP-2 essential for cranial closure and craniofacial development. Nature 381, 235-8.

Seberg, H.E., Van Otterloo, E., Loftus, S.K., Liu, H., Bonde, G., Sompallae, R., Gildea, D.E., Santana, J.F., Manak, J.R., Pavan, W.J., et al. (2017). TFAP2 paralogs regulate melanocyte differentiation in parallel with MITF. PLoS Genet. 13, e1006636.

Song, R., and Yosypiv, I.V. (2011). Genetics of congenital anomalies of the kidney and urinary tract. Pediatr. Nephrol. 26, 353-364.

Sugano, Y., Cianciolo Cosentino, C,, Loffing-Cueni, D., Neuhauss, S.C.F., and Loffing, J. (2017). Comparative transcriptomic analysis identifies evolutionarily conserved gene products in the vertebrate renal distal convoluted tubule. Pflugers Arch. 469, 859-867. 
Takasato, M., and Little, M.H. (2017). Making a kidney organoid using the directed differentiation of human pluripotent stem cells. Methods Mol. Biol.1597,195-206.

Van Otterloo, E., Li, W., Bonde, G., Day, K.M., Hsu, M.Y., and Cornell, R.A. (2010). Differentiation of zebrafish melanophores depends on transcription factors AP2 alpha and AP2 epsilon. PLoS Genet. 6 , e1001122.

Van Otterloo, E., Li, H., Jones, K.L., and Williams, T. (2018). AP-2 $\alpha$ and AP-2 $\beta$ cooperatively orchestrate homeobox gene expression during branchial arch patterning. Development 145, pii: dev157438.

Wang, I.J., Tsai, R.J., Yeh, L.K., Tsai, R.Y., Hu, F.R., and Kao, W.W. (2011). Changes in corneal basal epithelial phenotypes in an altered basement membrane. PLoS One 6, e14537.

Wang J, Ji W, Zhu D, Wang W, Chen Y, Zhang Z, and Li F. (2018). Tfap2b mutation in mice results in patent ductus arteriosus and renal malformation. J. Surg. Res. 227, 178-185.

Westerfield, M. (1993). The Zebrafish Book. Eugene, USA: University of Oregon Press.

Wingert, R.A., Brownlie, A., Galloway, J.L., Dooley, K., Fraenkel, P., Axe, J.L., Davidson, A.J., Barut, B., Noriega, L., Sheng, X., et al. (2004). The chianti zebrafish mutant provides a model for erythroidspecific disruption of transferrin receptor 1. Development 131, 6225-6235.

Wingert, R.A., Selleck, R., Yu, J., Song, H.D., Chen, Z., Song, A., Zhou, Y., Thisse, B., Thisse, C., McMahon, A.P., et al. (2007). The cdx genes and retinoic acid control the positioning and segmentation of the zebrafish pronephros. PLoS Genet. 3, 1922-1938.

Wingert, R.A., and Davidson, A.J. (2008). The zebrafish pronephros: a model to study nephron segmentation. Kidney Int. 73, 1120-1127.

Wingert, R.A., and Davidson A.J. (2011). Zebrafish nephrogenesis involves dynamic spatiotemporal expression changes in renal progenitors and essential signals from retinoic acid and irx3b. Dev. Dyn. 240, 2011-2027.

Zhang, J., Hagopian-Donaldson, S., Serbedzija, G., Elsemore, J., Plehn-Dujowich, D., McMahon, A.P., Flavell, R.A., and Williams, T. (1996). Neural tube, skeletal and body wall defects in mice lacking transcription factor AP-2. Nature 381, 238-241.

Zhang, J., Yuan, S., Vasilyev, A., and Amin Arnaout, M. (2015). The transcriptional coactivator Taz regulates proximodistal patterning of the pronephric tubule in zebrafish. Mech. Dev. 3, 328-335. 


\section{Figure 1: Forward genetic screen reveals tfap2a is necessary for nephrogenesis in the developing} CS: corpuscle of Stannius, DL: distal late segment, CD: collecting duct). B. Screening approach by WISH of alternating nephron compartment markers wt1b/s/c20a1a/s/c12a1 (P/PCT/DE) in WT and trm at $24 \mathrm{hpf}$. Scale bar $=70 \mu \mathrm{m}$. C. SNPtrack results from whole genome sequencing concentration of SNPs at chromosome 24. Confirmation of G -> A tfap2a mutation by direct PCR sequencing of trm ${ }^{-/}$embryos. Exon diagram of tfap2a depicts 3 alternative spliceoforms (pink, cyan, orange lines). Black *'s indicate alternative start sites. tfap2a MO-splice (blue) targets 3' end of exon 2. tfap $2 a^{m 819}$ lesion (red x) generates stop codon in exon 5. $\operatorname{trm} \mathrm{G}>\mathrm{A}$ mutation (red) maps to 3' end of exon 1c. Green letters indicate conserved splice residues. RT-PCR primers used for RT-PCR analysis flank intron 1-2 (purple arrows). D. RT-PCR analysis of control (WT) embryos, WT trm siblings, and trm ${ }^{-/}$. Mutant bands are labeled 1-4 in green. Table indicates predicted genetic consequence from sequencing the mutant bands. (TAD:transcriptional activation domain, DBD:DNA binding domain). E. Failure to complement revealed by WISH analysis of

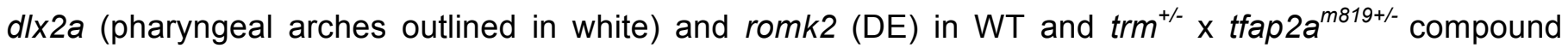
mutants. Scale bars $=70 \mu \mathrm{m}, 35 \mu \mathrm{m}$. F. Live imaging at $4 \mathrm{dpf}$ reveals abnormal craniofacial cartilage (black arrowhead) and pericardial edema (blue arrowhead) in $\mathrm{trm}^{-/}$and tfap2a morphants. Scale bar $=200$ $\mu \mathrm{m}$. G. Alcian Blue cartilage staining in WT and $\mathrm{trm}^{-/-}$at $4 \mathrm{dpf}$. Gaping jaw phenotype indicated by black arrowhead. Black dotted lines are utilized to trace Meckel's cartilage. Scale bar $=100 \mu \mathrm{m}$. H. Whole mount denotes $40 x$ optical zoom. Scale bar $=30 \mu \mathrm{m}$. expression (purple) at the 10,15, 20, 24, and 28 ss. smyhc1 (red) was used to mark somites. Black boxes indicate tfap2 expression domains within developing renal progenitors. Scale bar $=200 \mu \mathrm{m}$. B. Double FISH of WT tfap2a (green) and tfap2b (red) transcript expression at 10 ss (flat mount), 20 ss, and 28 ss (lateral views). DAPI (blue) labels nuclei. White arrowheads demarcate cellular regions of overlapping transcripts within the pronephros. Scale bar $=70 \mu \mathrm{m}$. C. Double FISH of slc12a1 (pink) and tfap2a (green) in WT embryo at $24 \mathrm{hpf}$. White box indicates area featured in bottom panel (60x z-stack). White dotted line outlines nephron tubule. DAPI (blue) labels nuclei. Scale bars $=70 \mu \mathrm{m}, 10 \mu \mathrm{m}$. D. WISH analysis of tfap $2 b$ expression in WT and trm $^{-/}$. Arrowhead indicates differential hindbrain expression of tfap2b. Black box designates tfap $2 b$ expression within pronephros. Scale bars $=100 \mu \mathrm{m}, 50 \mu \mathrm{m}$. E. WISH analysis of tfap $2 a$ 
1033

1034

1035

1036

1037

1038

1039

1040

1041

1042

1043

1044

1045

1046

1047

1048

1049

1050

1051

1052

1053

1054

1055

1056

1057

1058

1059

1060

1061

1062

1063

1064

1065

1066

1067

1068

1069
$100 \mu \mathrm{m}, 50 \mu \mathrm{m}$. F. Quantification of absolute length measurements of tfap $2 b$ expression domain within pronephros. G. Quantification of absolute length measurements of tfap2a expression domain within pronephros. $\mathrm{n}=3$ for each control and test group. Absolute measurements (in microns) were analyzed by unpaired t-tests. Data are represented as \pm SD. ${ }^{* * *} p<0.001$, N.S. $=$ not significant.

\section{Figure 3: tfap2a and tfap2b function redundantly to activate distal nephron solute transporter} signature. A. WT and $t^{-/-}$embryos were microinjected with combinations of tfap $2 a$ and tfap $2 b$ spliceMOs. WISH was used to stain embryos for slc12a1 (DE, purple), s/c12a3 (DL, red), and clcnk (Pandistal, purple) at $24 \mathrm{hpf}$. Black bars indicate WT marker domains. Scale bar $=35 \mu \mathrm{m}$. B. Quantification of absolute length of slc12a1 expression domain. C. Quantification of absolute length measurements of slc12a3 expression domain. D. Quantification of absolute length measurements of clcnk expression domain. $\mathrm{n} \geq 4$ for each control and test group. Measurements were compared by ANOVA. Data are represented as $\pm S D$. ${ }^{*} p<0.05,{ }^{* *} p<0.01$, Green brackets indicate not statistically significant.

Figure 4: tfap2a is necessary and sufficient to drive the DE gene expression program. A. trm ${ }^{-/-}$ /hs:tfap2a and hs:tfap2a were heat-shocked at the 8 ss to overexpress WT Tfap2a protein for rescue and gain of function studies. WT embryos were microinjected with tfap2a cRNA for an independent gain of function studies. Control and experimental samples subjected to WISH analysis for romk2 (DE) expression at $24 \mathrm{hpf}$. Black bar indicates WT romk2 domain. Scale bars $=70 \mu \mathrm{m}$. B. Quantification of absolute length measurements of romk2 expression domain. $\mathrm{n} \geq 4$ for each control and test group. Measurements were compared by ANOVA. Data are represented as $\pm S D$. ${ }^{* *} p<0.01$, Green brackets indicate not statistically significant. HS+ (red) signifies application of heat-shock. HS- (black) indicates no heat-shock. +tfap2a cRNA (blue) represents microinjection of tfap2a capped RNA at the 1-cell stage. C. Double FISH analysis of slc12a1 (DE, green) and slc12a3 (DL, red) in WT and heat shock-treated hs:tfap2a embryos at 24 hpf. Scale bar $=20 \mu \mathrm{m}$. White box indicates area imaged at higher (60X) objective in C'. C'. DAPI only (above) and merged channels (below). Dotted white line outlines a single cell coexpressing slc12a1 and slc12a3 transcripts. D. Double FISH analysis of s/c9a3 (panproximal, red) and s/c12a1 (DE, green) in WT and heat shock-treated hs:tfap2a embryos at $24 \mathrm{hpf}$. Scale bar $=35 \mu \mathrm{m}$. White box indicates area imaged at higher (60X) objective in D'. D'. DAPI (above) and merged channels (below). Dotted white line outlines a single cell coexpressing slc9a3 and s/c12a1 transcripts. DAPI (blue) labels nuclei.

Figure 5: tfap2a is essential for the induction of terminal differentiation, but not cell proliferation, survival, polarity or ciliogenesis within the distal nephron. A. WISH used to stain dlx2 (pharyngeal arches, purple), s/c9a3 (panproximal, purple), and s/c12a3 (DL, red) performed on 24 hpf WT and trm ${ }^{-/}$ 
1070

1071

1072

1073

1074

1075

1076

1077

1078

1079

1080

1081

1082

1083

1084

1085

1086

1087

1088

1089

1090

1091

1092

1093

1094

1095

1096

1097

1098

1099

1100

1101

1102

1103

1104

1105 embryos to assess nephron patterning. Black dotted lines indicate presumptive area occupied by DE progenitors. Scale bars $=70 \mu \mathrm{m}$. B. WISH analysis of $d l x 2$ and renal specification markers that span entire tubule (cdh17 and hnf1ba) in WT and trm ${ }^{-/}$at $24 \mathrm{hpf}$. Green boxes indicate continuous expression of tubule markers in DE. Scale bar $=70 \mu \mathrm{m}$. C. Whole mount FISH and IF to visualize proliferating DE cells (s/c12a1, green) in WT and trm ${ }^{-/}$at 24 hpf. anti-ph3 (red) labels proliferation. White dotted lines outline pronephric tubule (bottom). Scale bar $=10 \mu \mathrm{m}$. D. Acridine orange assay reveals no detectable difference in dying cell number (green) in WT and trm $^{-/}$at $24 \mathrm{hpf}$. White box indicates inset (optical zoom) of distal nephron area. Scale bar $=70 \mu \mathrm{m}$. E. Survey of epithelial polarity proteins by whole mount IF in WT and $\mathrm{trm}^{-/}$at $4 \mathrm{dpf}$. anti-Na,K-ATPase (red) was used as a basolateral marker and anti-aPKC (green) was used as an apical marker. Top image represents WT Na,K-ATPase protein expression in $4 \mathrm{dpf}$. White boxes indicate region in E'. Scale bars $=200 \mu \mathrm{m}, 10 \mu \mathrm{m}$. E'. Regions highlighted in B showing normal protein localization. F. Whole mount FISH with IF to assess cilia (anti-acetylated tubulin, green) morphology in the DE (s/c12a1, red) of WT and trm ${ }^{-/}$at 24 hpf. White dotted lines demarcate nephron. Scale bar $=10 \mu \mathrm{m}$. DAPI (blue) labels nuclei.

Figure 6: tfap2a interplays with the Iroquois homeobox genes irx3b and irx1a during nephrogenesis. A. Whole mount double FISH in 20 ss WT animals reveal tfap2a transcripts (green) and irx3b transcripts (red) are coexpressed distal pronephros. White box focuses on area of intense coexpression. Bottom panel indicates area outlined by white box at 60X magnification. DAPI (blue) labels nuclei. Scale bars $=70 \mu \mathrm{m}, 10 \mu \mathrm{m}$. B. Top panel: WISH for irx3b (purple) and smyhc1 (red) in WT and tfap2a morphants at $24 \mathrm{hpf}$. White dotted line indicates irx3b expression domain, which does not change due to tfap2a-deficiency. Bottom panel: WISH for tfap2a expression in irx3b morphants at 24 hpf. Black box indicates presence of tfap2a transcripts in DE segment domain in WT. Red box indicates absence of tfap2a transcripts in DE segment domain in irx3b morphants. Red asterisks $\left(^{*}\right)$ indicate loss of tfap2a expression within the neural crest streams in irx3b morphants. Scale bar $=70 \mu \mathrm{m}$. C. Quantification of tfap2a expression domain length. Measurements were compared by unpaired t-test. Data are represented as $\pm \mathrm{SD}$. ${ }^{* * *} \mathrm{p}<0.001$. D. WISH reveals reduced irx1a expression in trm $^{-/-}$and tfap2a morphants as compared to WT at $24 \mathrm{hpf}$. Scale bar $=35 \mu \mathrm{m}$. E. WISH of irx1a expression in hs:tfap2a untreated and heat shock-treated (red HS+) at $24 \mathrm{hpf}$. Black dotted lines denotes increased expression of irx1a in heat shock-treated $h s: t f a p 2 a$ embryos. Scale bar $=35 \mu \mathrm{m}$. F. Quantification of irx1a expression domain length in WT, hs:tfap2a (untreated), trm ${ }^{-/}$, tfap2a morphants, and heat shock treated (red HS+) hs:tfap2a. Measurements were compared by ANOVA. Data are represented as \pm SD. ${ }^{* *} p<0.01$, Green brackets indicate not statistically significant. 
Figure 7: tfap2a and tfap2b function in a proposed genetic regulatory network to control distal nephron differentiation. A. Schematic comparing DE progenitor maturation in WT and trm ${ }^{-/}$. Mutant cells display no perturbations in the early specification of the renal lineage (marked by Ihx1a, pax2a, and hnf1ba). Mutant progenitors undergo segment specification and exhibit features of mature epithelium (cdh17, Na,K-ATPase, and acetylated tubulin). In the final phase of differentiation, mutant cells fail to express DE-specific solute transporters (s/c12a1, romk2, and clcnk). B. Diagram depicts tfap2a distal nephron GRN. irx3b promotes tfap2a expression, and tfap2a functions upstream of irx1a (green arrows). tfap2a acts upstream of $t f a p 2 b$ as the core regulator of solute transporter expression (orange arrows). tfap2b functions redundantly (purple dotted line) to activate distal solute transporters (romk2, s/c12a1, clcnk, and slc12a3).

\section{Supplemental Figures \& Figure Legends}

S1 Figure: Tfap2a amino acid sequence is highly conserved across vertebrate species. Depicts tools. DNA-binding and dimerization motifs (blue line) display a high degree of sequence similarly ( $>90$ percent). Black boxes mark conserved residues.

S2 Figure: tfap2a MO splice efficacy verification through RT-PCR analysis. A. tfap2a exon map, indicating tfap2a MO-splice (red) targets the 3' end of exon 2. Forward and reverse primers used for RTPCR analysis are situated within exon 2 and exon 3 (green arrows). B. Image of RT-PCR gel reveals presence of a larger product size in the morphant lane, indicating disrupted splicing. $1=$ WT band, $2=$ morphant band. C. Table presenting the sequencing results of each band. D. WT and tfap2a morphant amino acid sequences. Inclusion of intron 2-3 results in premature stop codon (red), and a predicted truncated protein in tfap2a morphants.

S3 Figure: tfap2b MO splice efficacy verification through RT-PCR analysis. A. tfap2b exon map, indicating tfap2b MO-splice (red) targets the 3' end of exon 4. Forward and reverse primers used for RTPCR analysis are situated within exon 4 and exon 5 (green arrows). B. Image of RT-PCR gel reveals presence of a larger product size in the morphant lane, indicating disrupted splicing. $1=$ WT band, $2=$ 
1142 amino acid sequences. Inclusion of intron 4-5 results in premature stop codon (red), and a predicted

1143 truncated protein in tfap2b morphants.

S4 Figure : trm $^{-/}$mutant embryos exhibit normal filtration and proximal tubule fluid uptake at 3 dpf.

A. WISH analysis of DE markers (s/c12a1 and romk2) in WT and trm ${ }^{-/}$mutants at $4 \mathrm{dpf}$. Scale bars $=200$ $\mu \mathrm{m}, 50 \mu \mathrm{m}$. B. Kidney function assay was performed by injecting $40 \mathrm{kD}$ Dextran FITC into the circulation of $2 \mathrm{dpf}$ WT and $\mathrm{trm}^{-/}$larvae. Images were collected 1-hour post injection and 24-hours post injection. Right panel: nephron tubules labeled with green fluorescence indicate endocytosis of Dextran. Scale bar $=150$ $\mu \mathrm{m}$. C. O-dianisidine staining of craniofacial vasculature in WT and $\mathrm{trm}^{-/-}$at $4 \mathrm{dpf}$. Abnormal cartilage is annotated by black arrowhead. Scale bar $=100 \mu \mathrm{m}$. have abrogated corpuscle of Stannius formation. A. WISH to evaluate proximal convoluted tubule (s/c20a1a) and proximal straight tubule (trpm7) in WT and $\mathrm{trm}^{-/}$at $24 \mathrm{hpf}$. Black arrowheads indicate the

1158 start and end of s/c20a1a expression. Scale bar $=50 \mu \mathrm{m}$. B. Quantification of absolute lengths of s/c20a1a expression. C. Quantification of absolute lengths of trpm7 expression. $\mathrm{n}=3$ for each control and test group. Measurements were compared by unpaired t-test. Data are represented as \pm SD. N.S. = not 
bioRxiv preprint doi: https://doi.org/10.1101/460105; this version posted November 2, 2018. The copyright holder for this preprint (which was not certified by peer review) is the author/funder, who has granted bioRxiv a license to display the preprint in perpetuity. It is made available under aCC-BY-NC 4.0 International license.

\section{Figure 1}

A

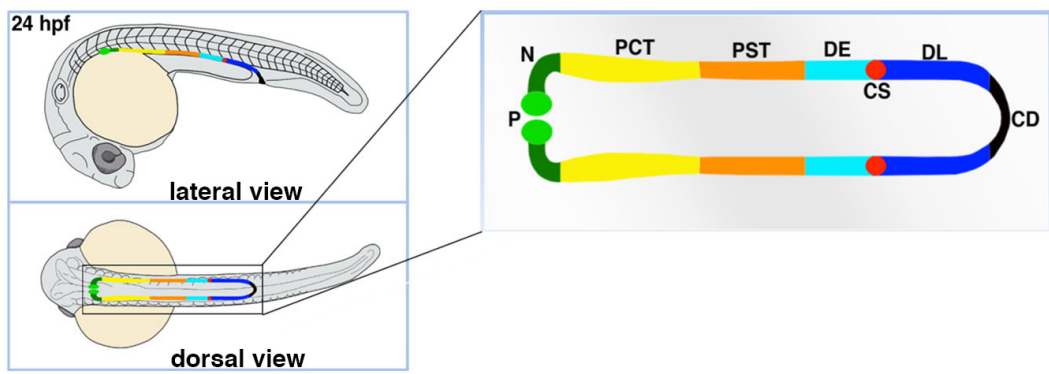

B

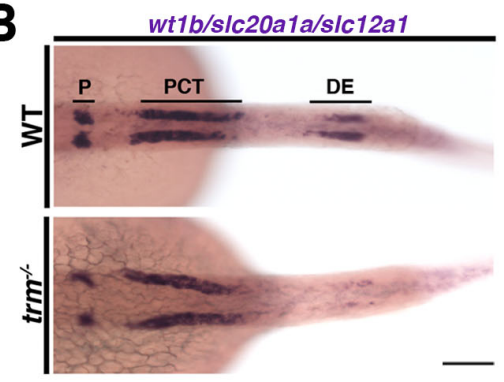

C

\section{(1)}
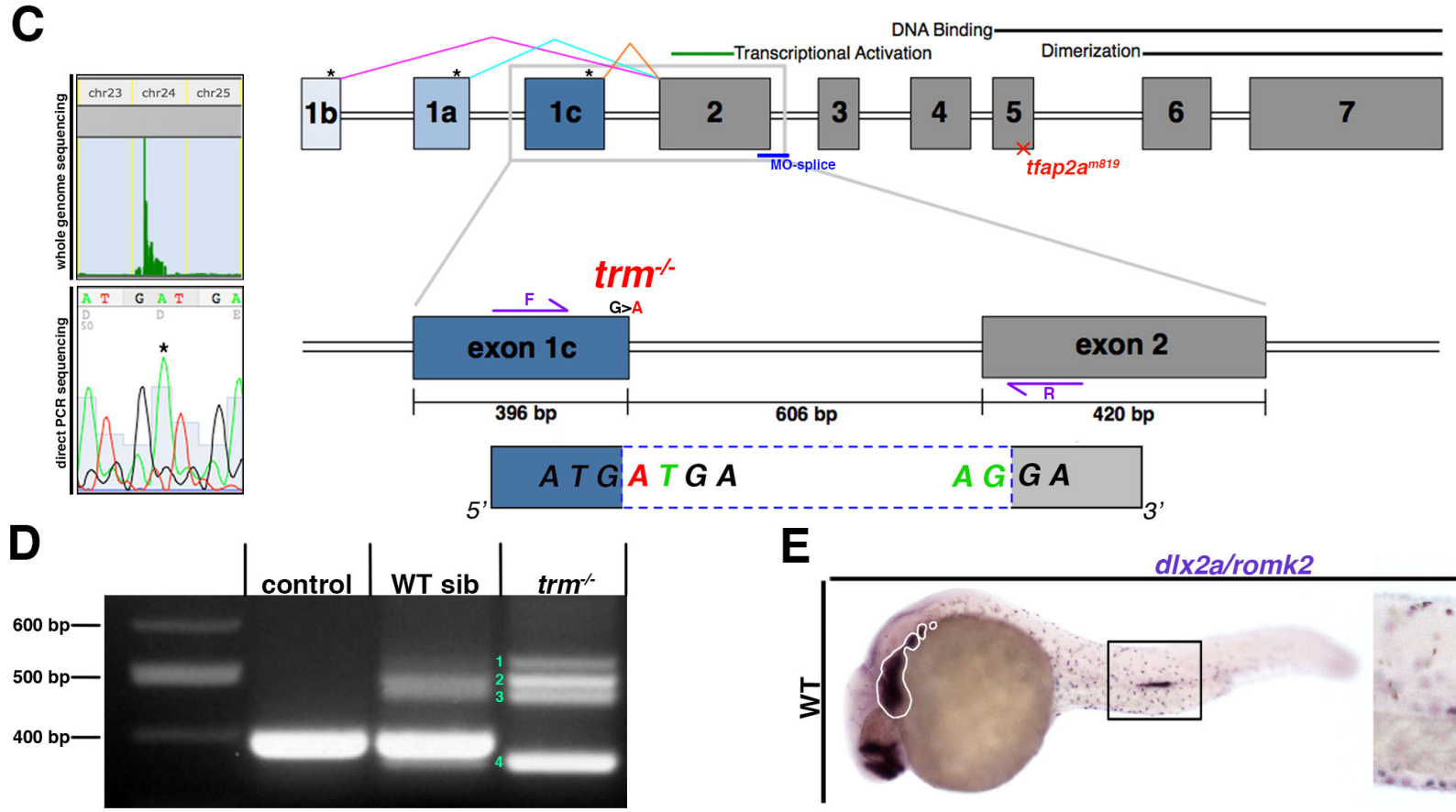

E

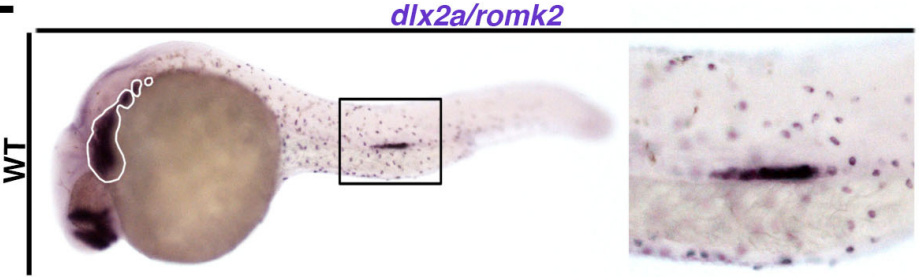

\begin{tabular}{|l|l|l|l|}
\hline & Reading Frame & Genetic Consequence & Protein Domain \\
\hline 1 & shift & premature stop & loss of TAD and DBD \\
\hline 2 & no shift & in frame addition of 38 aa & all domains present \\
\cline { 2 - 4 } 3 & shift & premature stop & loss of TAD and DBD \\
\hline 4 & shift & premature stop & loss of TAD and DBD \\
\hline
\end{tabular}
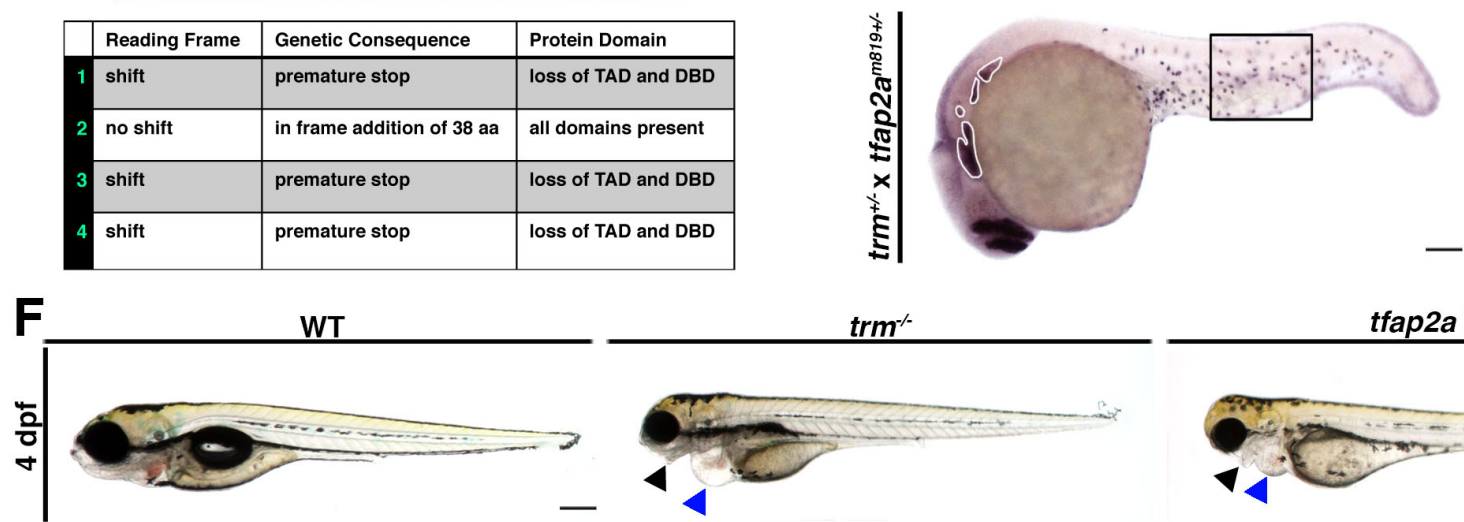

$\operatorname{trm}^{-/}$

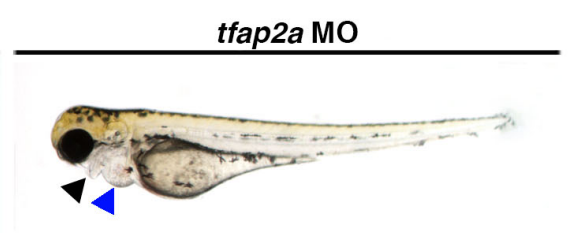

G

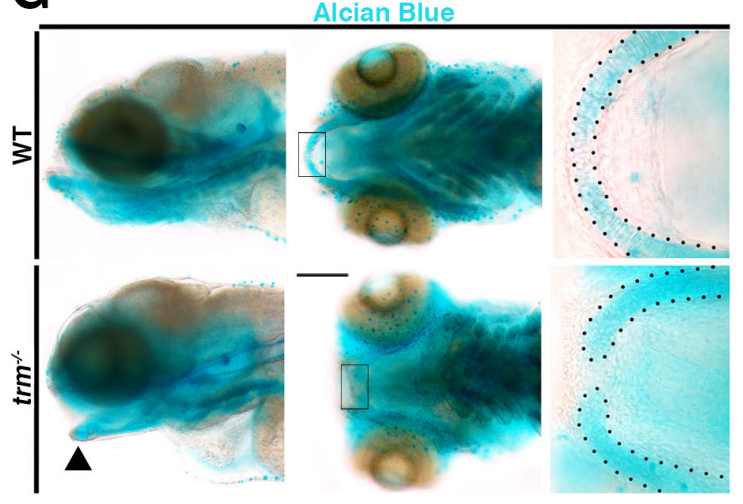

H

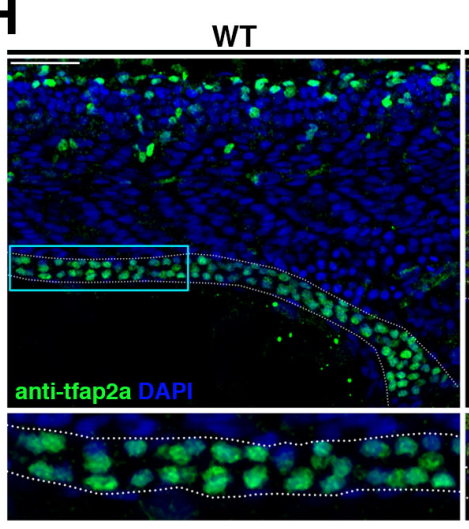

$\mathrm{trm}^{-/}$

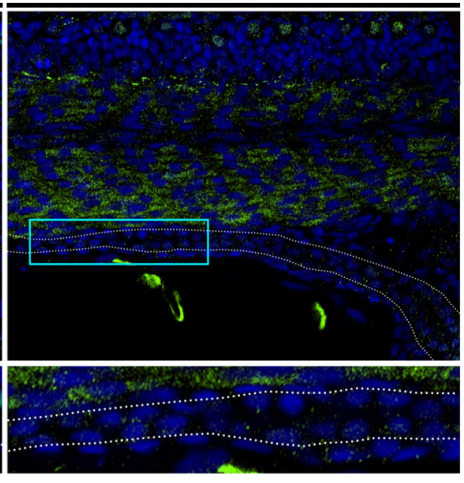


bioRxiv preprint doi: https://doi.org/10.1101/460105; this version posted November 2, 2018. The copyright holder for this preprint (which was not certified by peer review) is the author/funder, who has granted bioRxiv a license to display the preprint in perpetuity. It is made available under ACC-BY-NC 4.0 International license.

\section{Figure 2}

A

A tfap2a/smyhc1

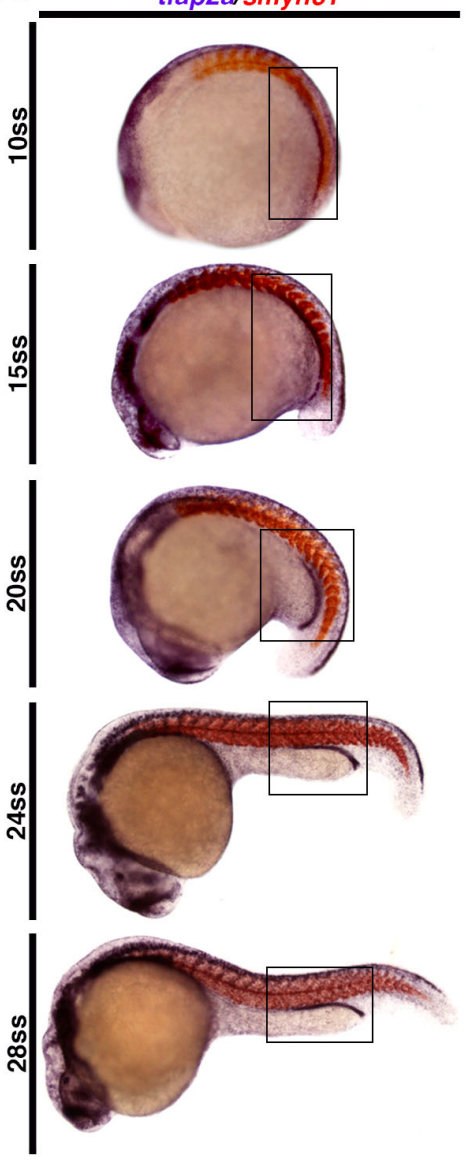

D
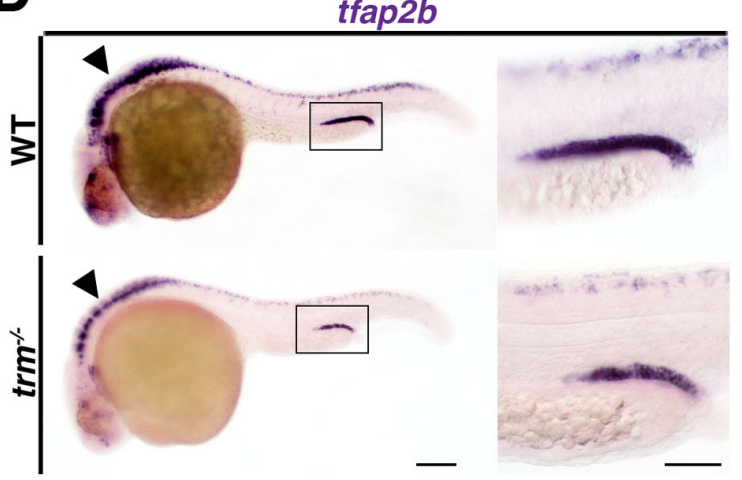

$\mathbf{F}$

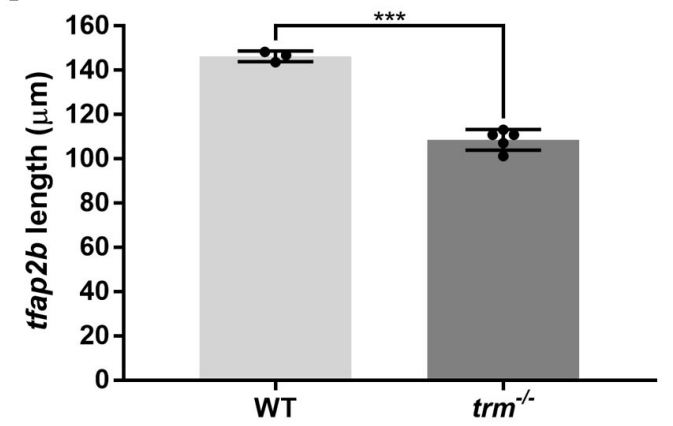

B

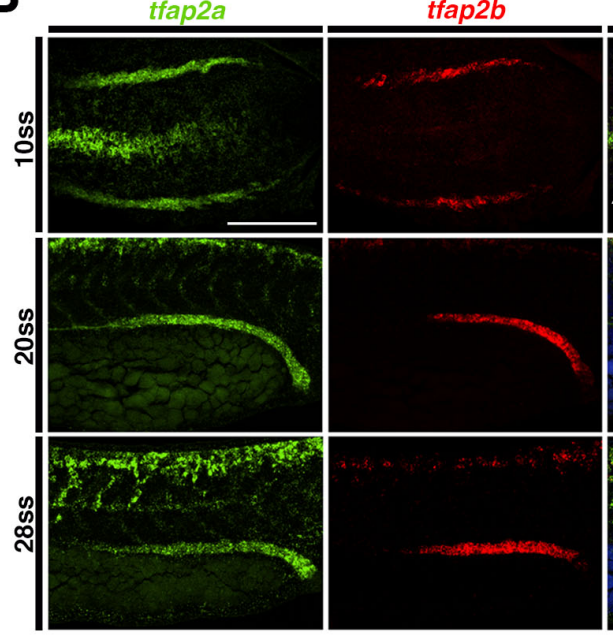

C

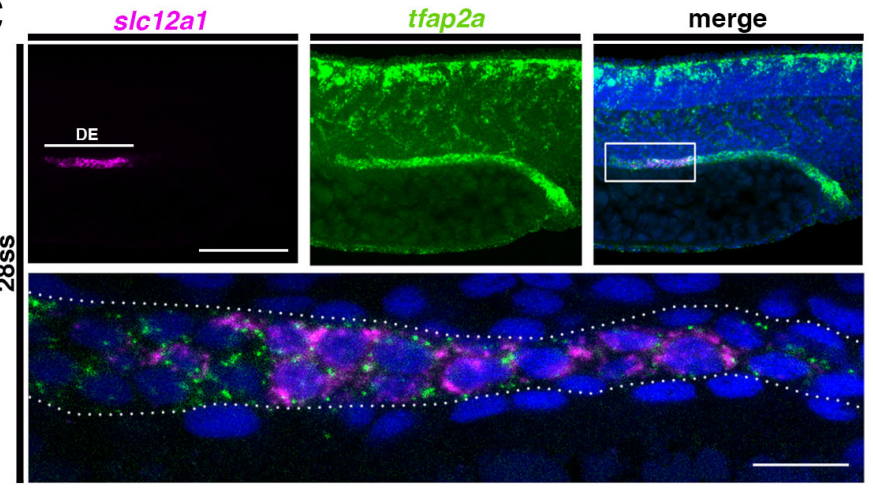

E
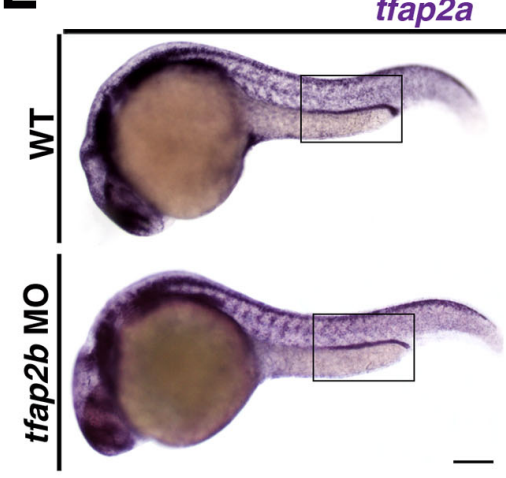

G

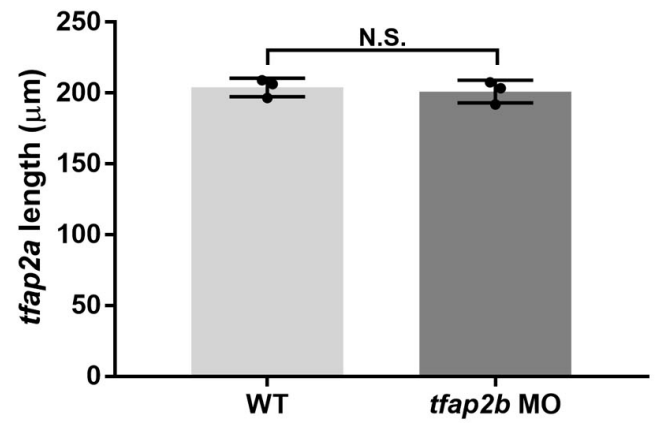


bioRxiv preprint doi: https://doi.org/10.1101/460105; this version posted November 2, 2018. The copyright holder for this preprint (which was not certified by peer review) is the author/funder, who has granted bioRxiv a license to display the preprint in perpetuity. It is made available under aCC-BY-NC 4.0 International license.

\section{Figure 3}

A
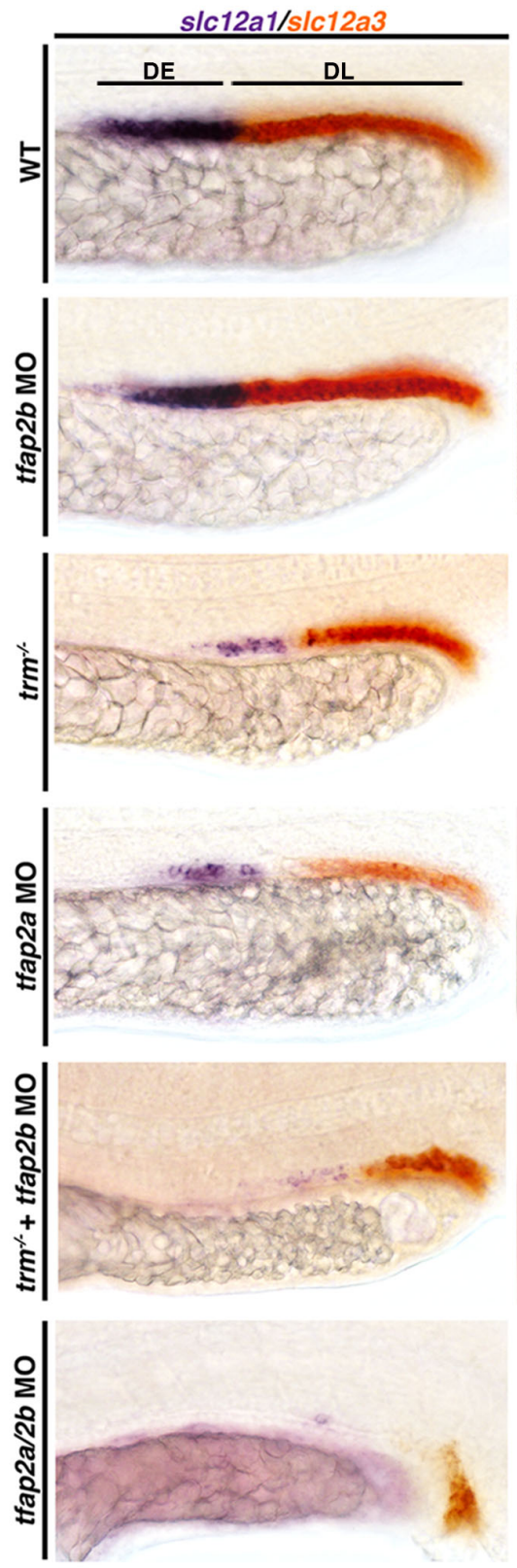

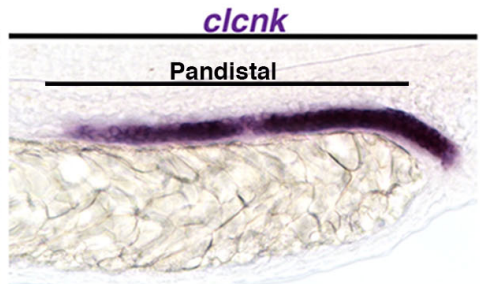

B
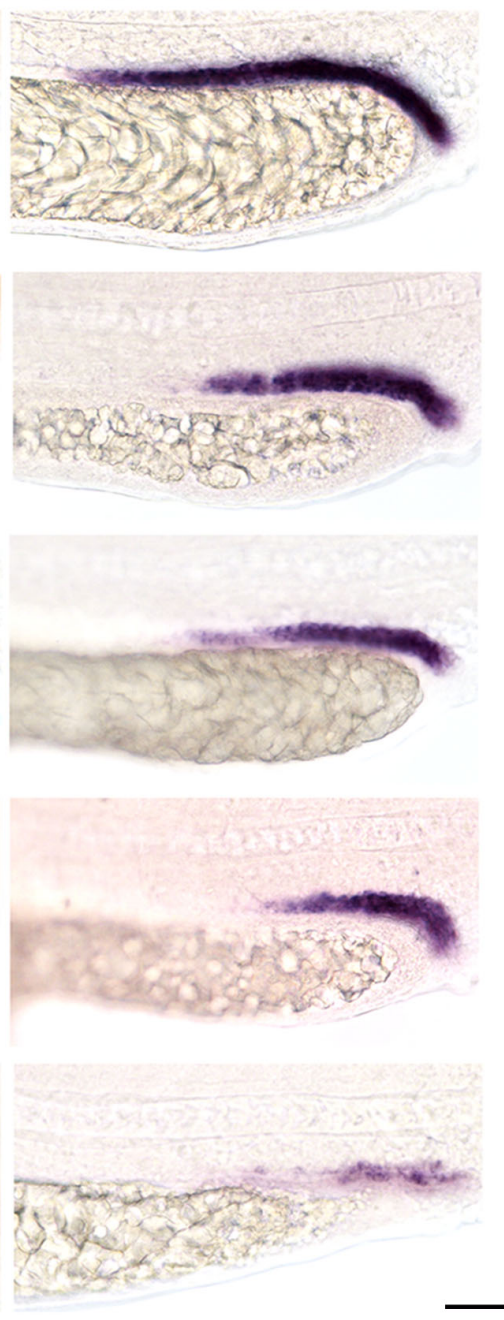

C

D
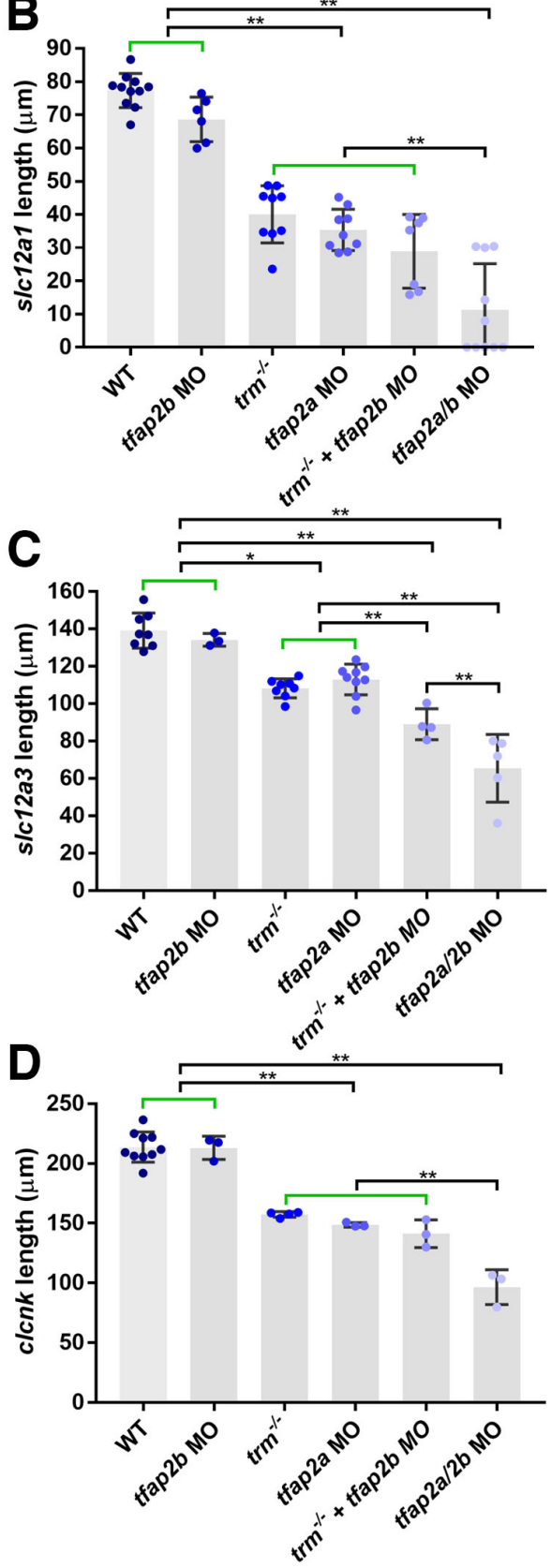
bioRxiv preprint doi: https://doi.org/10.1101/460105; this version posted November 2, 2018. The copyright holder for this preprint (which was not certified by peer review) is the author/funder, who has granted bioRxiv a license to display the preprint in perpetuity. It is made available under aCC-BY-NC 4.0 International license.

\section{Figure 4}

A
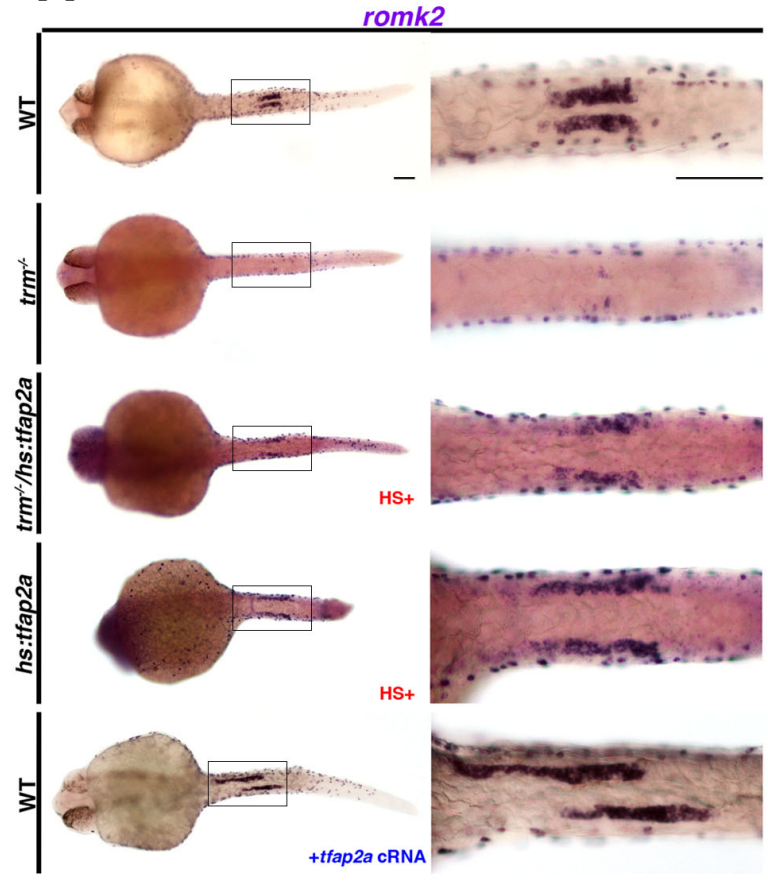

C
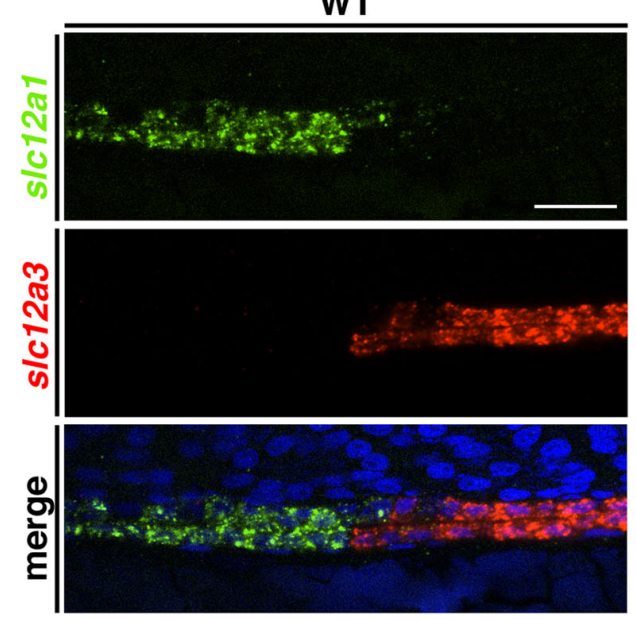

D
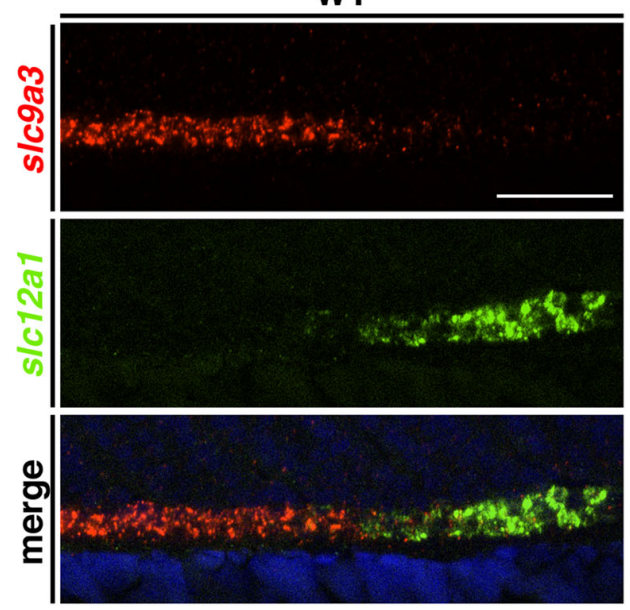

B

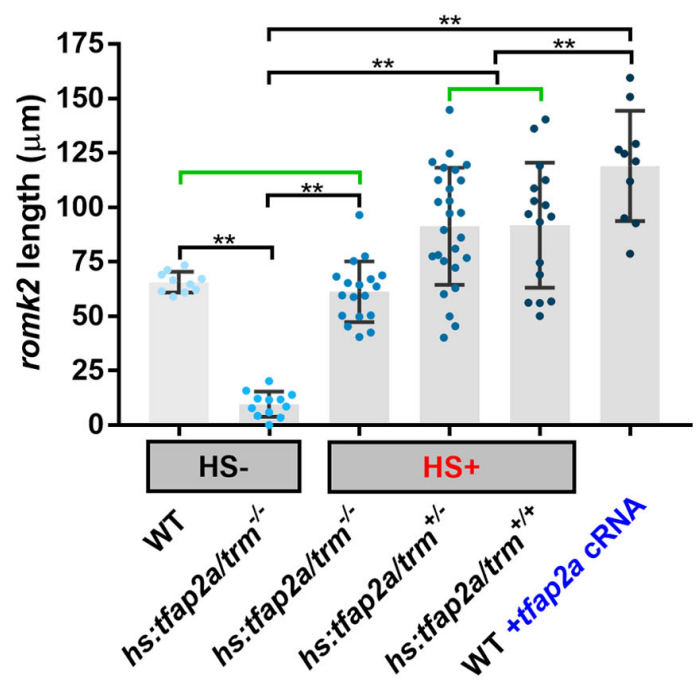

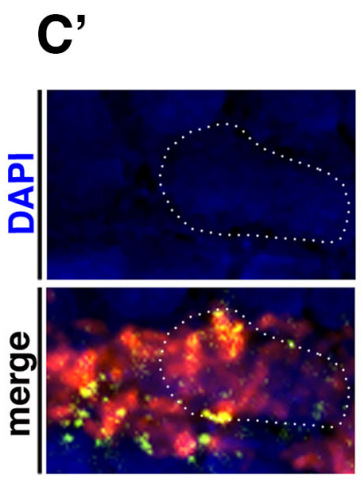

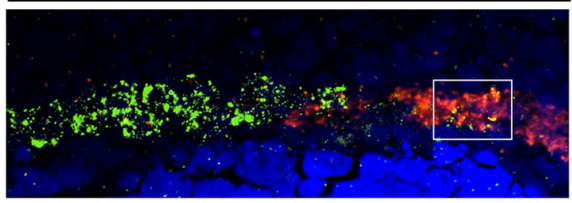

D'
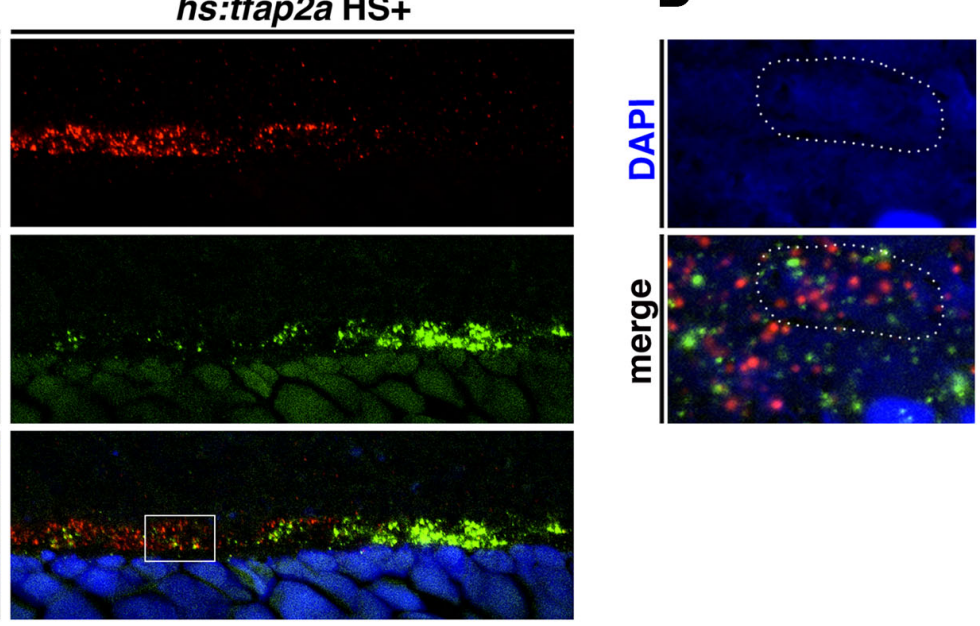
bioRxiv preprint doi: https://doi.org/10.1101/460105; this version posted November 2, 2018. The copyright holder for this preprint (which was not certified by peer review) is the author/funder, who has granted bioRxiv a license to display the preprint in perpetuity. It is made available under ACC-BY-NC 4.0 International license.

\section{Figure 5}

A

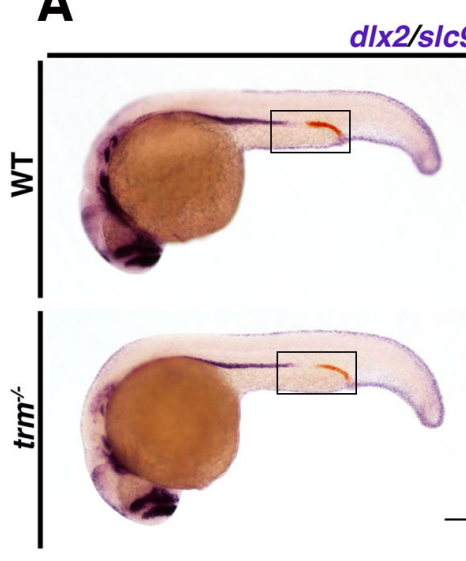

C

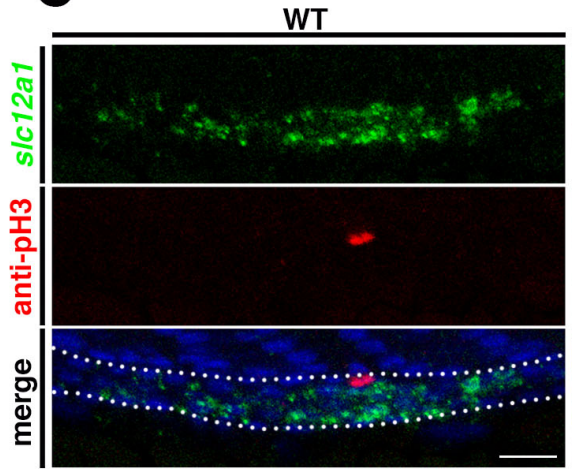

E
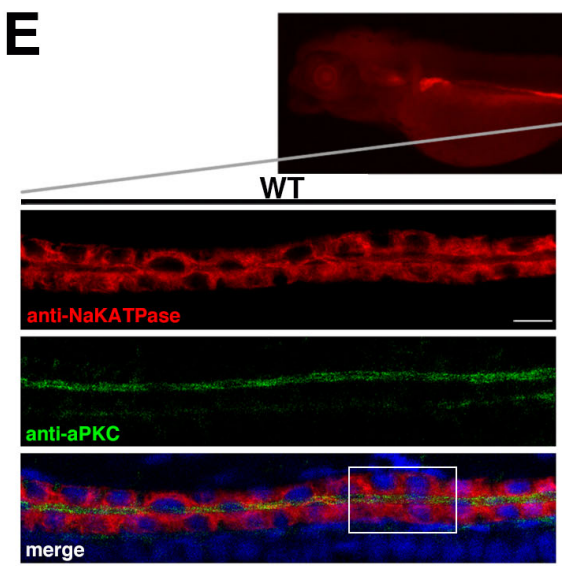

$\mathbf{F}$

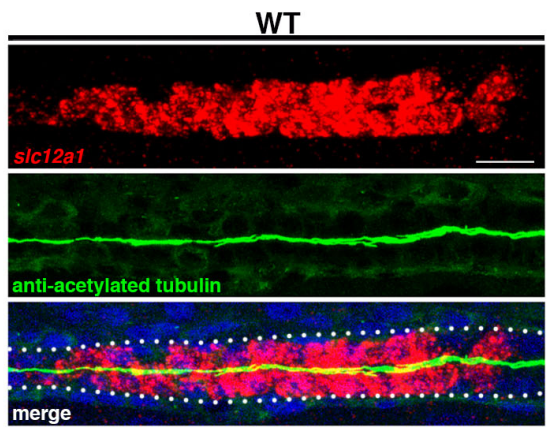

B
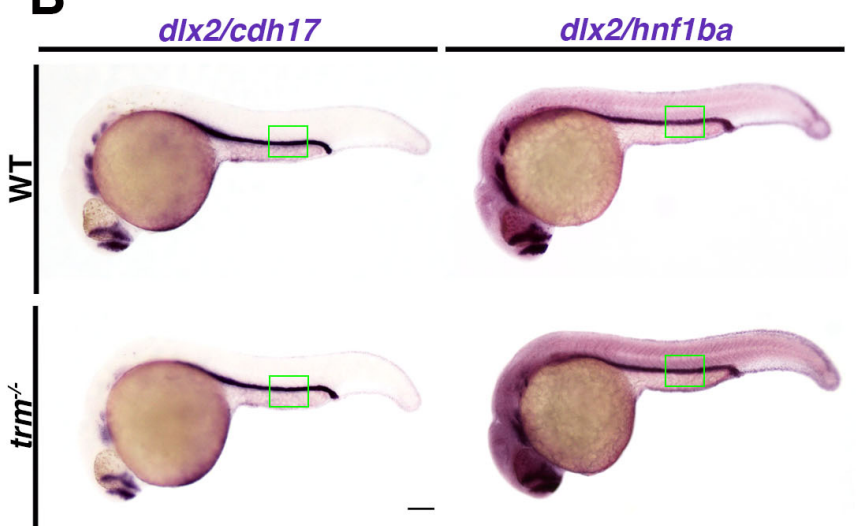

D

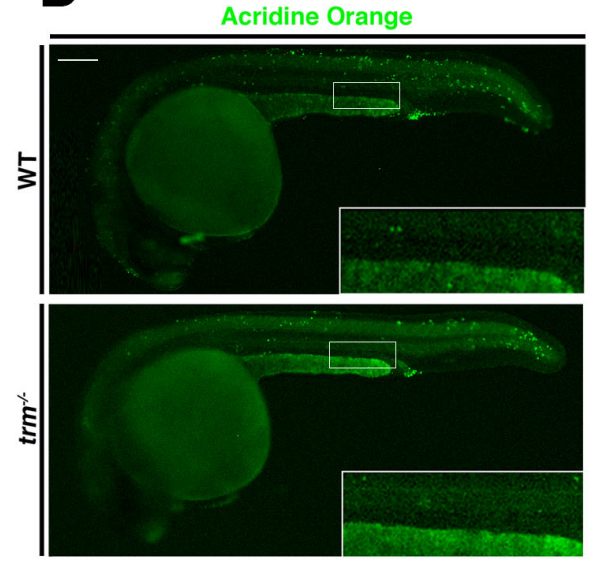

E'

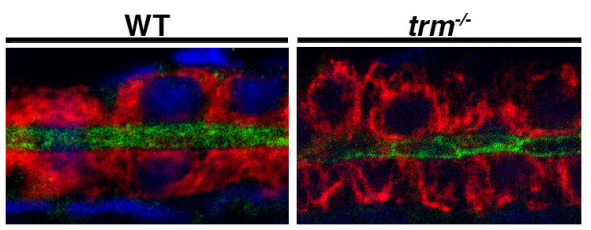

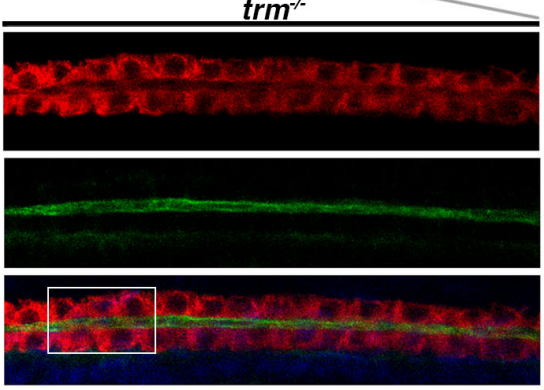

$t^{\prime \prime m}$

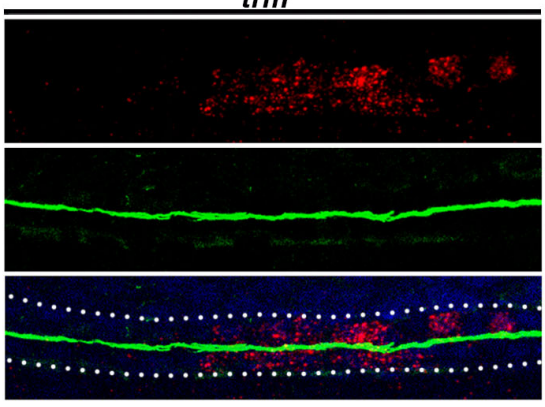


bioRxiv preprint doi: https://doi.org/10.1101/460105; this version posted November 2, 2018. The copyright holder for this preprint (which was not certified by peer review) is the author/funder, who has granted bioRxiv a license to display the preprint in perpetuity. It is made available under aCC-BY-NC 4.0 International license.

\section{Figure 6}
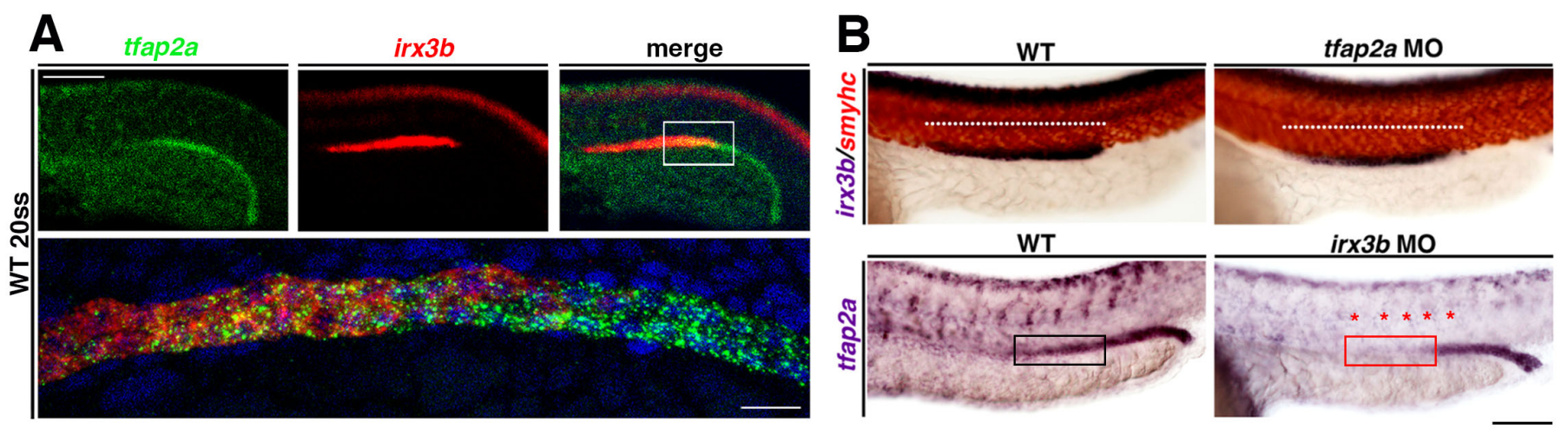

C

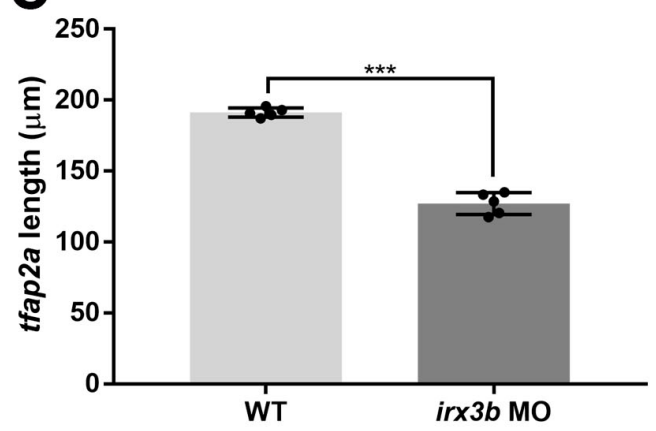

$\mathbf{E}$

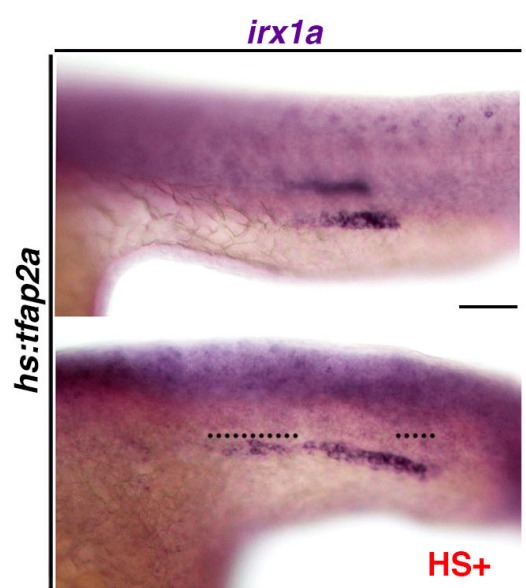

D

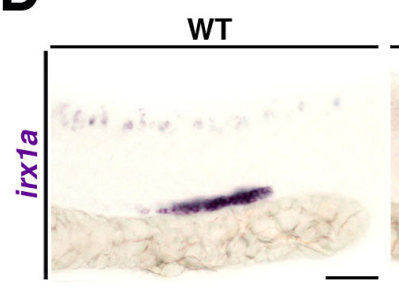

$\operatorname{trm}^{\circ-}$

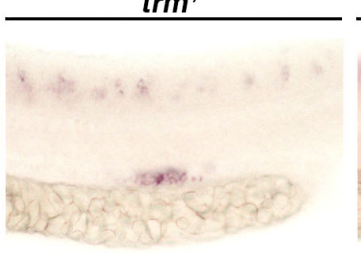

$\mathbf{F}$

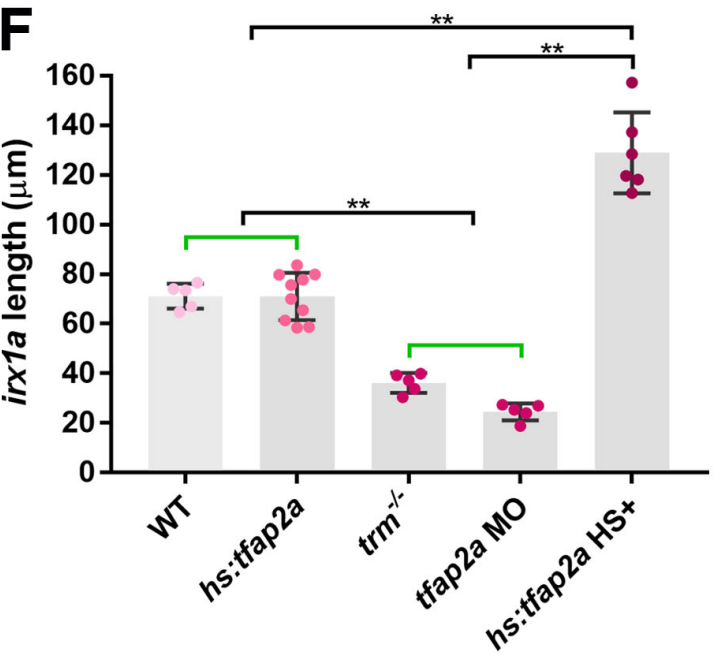

tfap2a MO

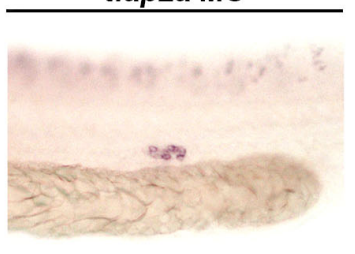


bioRxiv preprint doi: https://doi.org/10.1101/460105; this version posted November 2, 2018. The copyright holder for this preprint (which was not certified by peer review) is the author/funder, who has granted bioRxiv a license to display the preprint in perpetuity. It is made available under aCC-BY-NC 4.0 International license.

\section{Figure 7}

\section{A}

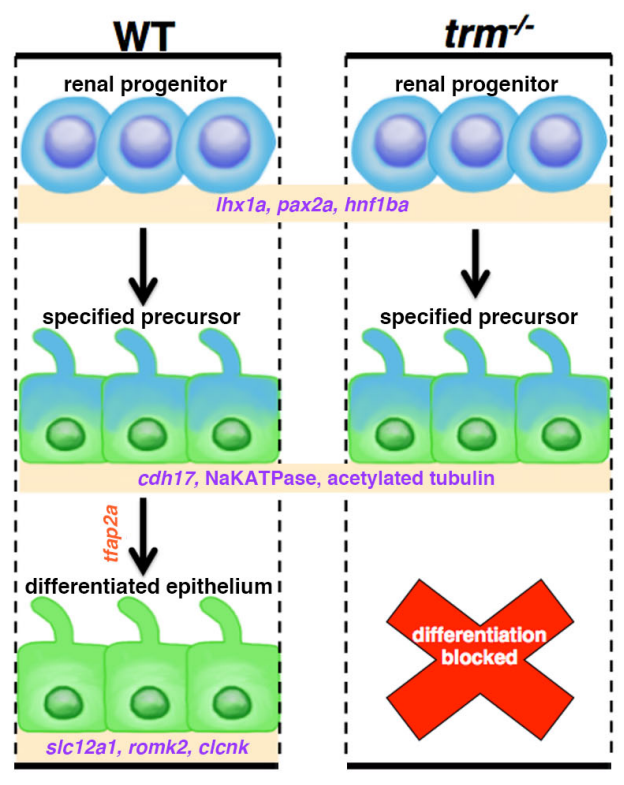

B

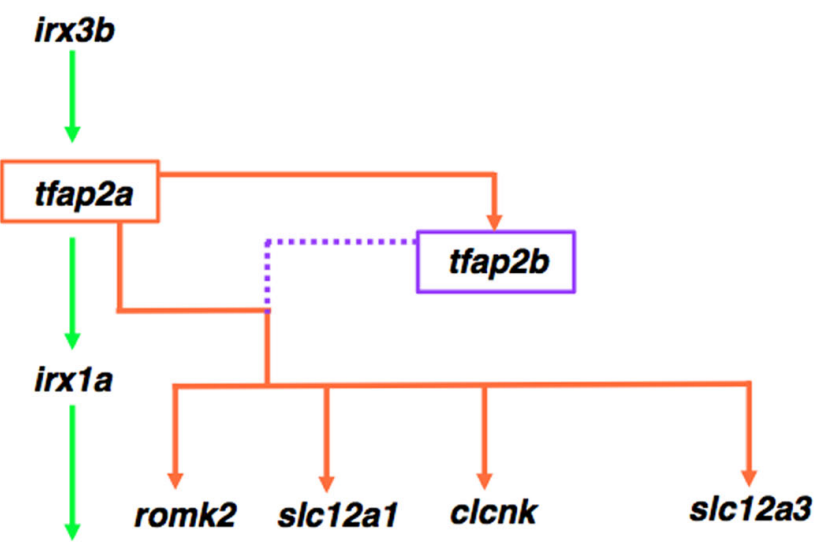

Distal Late 


\section{Figure S1}

\section{tfap2a protein alignment}

human

mouse

zebrafish

human

mouse

zebrafish

human

mouse

zebrafish

human

mouse

zebrafish

human

mouse

zebrafish

human

mouse

zebrafish

human

mouse

zebrafish

human

mouse

zebrafish
1

$\begin{array}{ll}1 & \mathrm{MNSVV} \\ 1 & \mathrm{MHCVK}\end{array}$

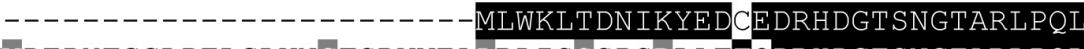

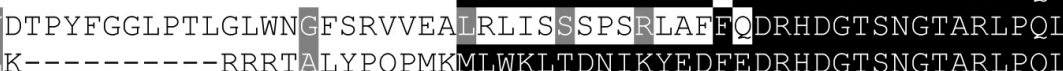

K--------RRRTALYPQPMKMLWKLTDNIKYEDFEDRHDGT SNGTARLPQI

32

61

51

GTVGQSPYTSAPPLSHTPNADFQPPYFP P PYQPIYPQSQDPYSHVNDPYSLNPLHAQPQP
GTVGQSPYTSAPPLSHTPNADFQPPYFPP PYQPIYPQSQDPYSHVNDPYSLNPLHAQPQP
GSVGQSPYTSAPPLSHTPNSDFQPPYFPP PYQP IYPQSQDPYSHVNDPYSINSLHAQSQA

92

121

111
152

181

166

LPFA

LPHA IEDVPHVEDPGINIPDOTVIKKGPVSISKSNSNAVSAIPINKDNLFGGVVNPNEV PHSLEDVQQVEDQG I H I P DQTVIKKGPVS ISKNNS-NISAIP INKDGLFGGVVNPNEVE

212

241

225

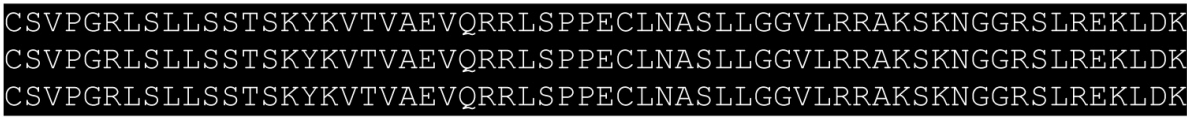

DNA-binding/Dimerization domain

272

301

285

IGLNLPAGRRKAANVTLLTSLVEGEAVHLARDFGYVCETEFPAKAVAEFLNRQHS DPNEQ IGLNLPAGRRKAANVTLLTS LVEGEAVHLARDFGYVCETEFPAKAVAEFLNRQHSDPNEQ IGLNLPAGRRKAANVTLLTSLVEGEAVHLARDFGYVCETEFPAKAIAEYMNRQHSDPNEQ

332

361

345

TRKNMLLATKQICKEFTDLLAQDRS P LGNSRPNP ILEPGIQSCLTHFNLISHGFGSPAV

ARKNMLLATKQICKEFTDLLAQDRSPLGNSRPNP I LEPG I SCLTHFNLISHGFGSPAV

QRKNMLLATKQ ICKEFTDLLSQDRS P LGNSRPQP I LEPG I QSCLTHESL I S HGFGTPAV

392

421

405 
bioRxiv preprint doi: https://doi.org/10.1101/460105; this version posted November 2, 2018. The copyright holder for this preprint (which was not certified by peer review) is the author/funder, who has granted bioRxiv a license to display the preprint in perpetuity. It is made available under aCC-BY-NC 4.0 International license.

\section{Figure S2}

A

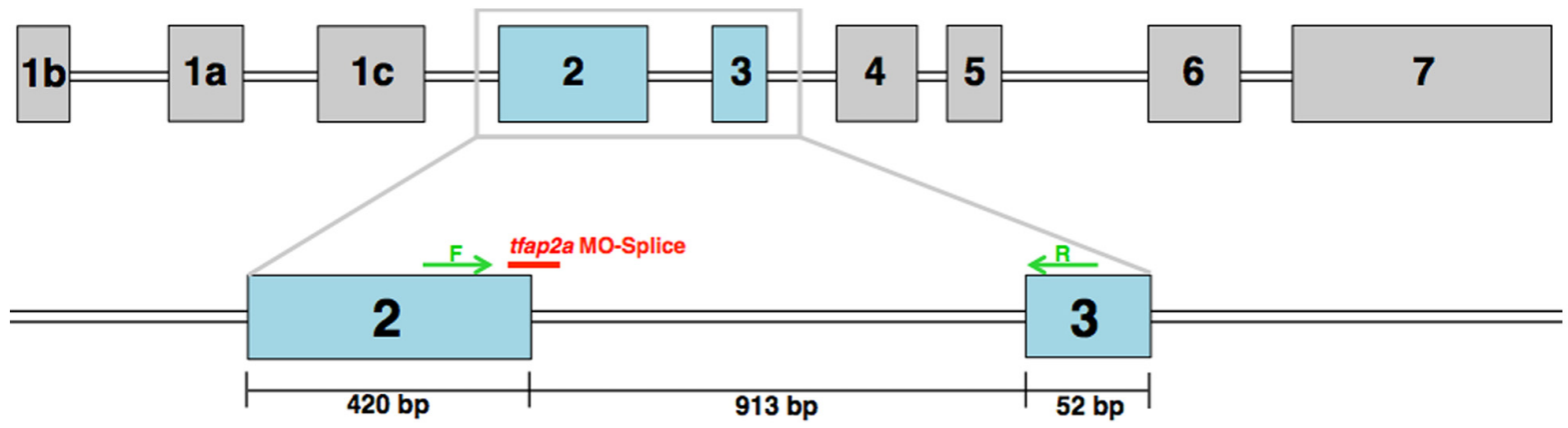

B

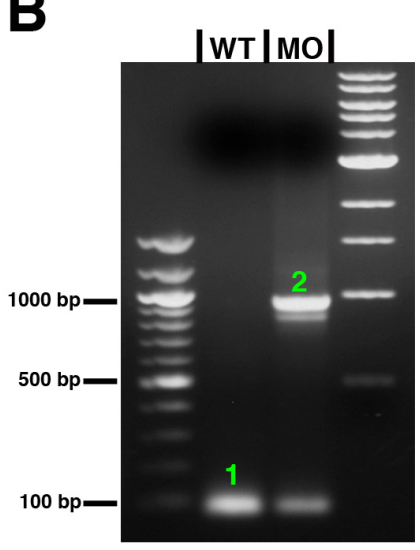

C

\begin{tabular}{|c|c|c|}
\hline Band & Size & Result \\
\hline 1 & $74 \mathrm{bp}$ & WT tfap2a \\
\hline 2 & $987 \mathrm{bp}$ & Inclusion of intron 2-3 \\
\hline
\end{tabular}

D

WT ...HSLEDVQ QVEDQGIHI...

exon 2 exon 3

MO ....HSLEDVQ VRRKAKILQCAAVQRDYSDFLLMHSTOP exon 2 intron 2-3 
bioRxiv preprint doi: https://doi.org/10.1101/460105; this version posted November 2, 2018. The copyright holder for this preprint (which was not certified by peer review) is the author/funder, who has granted bioRxiv a license to display the preprint in perpetuity. It is made available under aCC-BY-NC 4.0 International license.

\section{Figure S3}

A

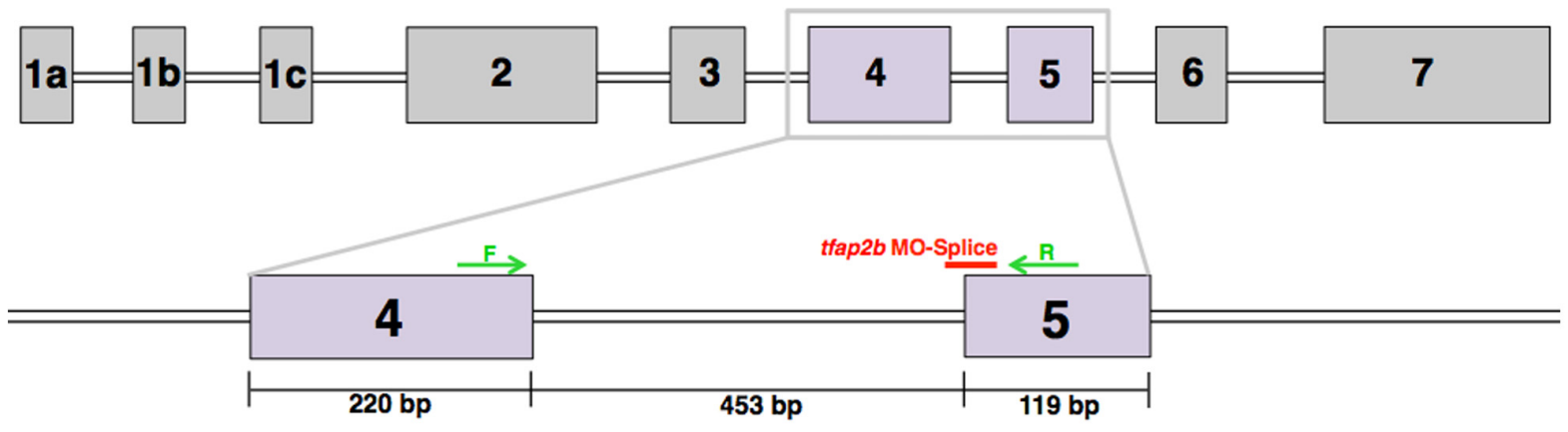

B

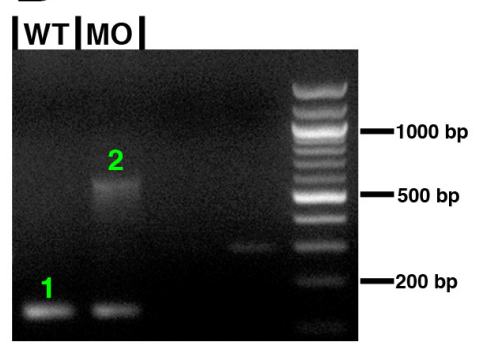

C

\begin{tabular}{|c|c|c|}
\hline Band & Size & Result \\
\hline 1 & $135 \mathrm{bp}$ & WT tfap2b \\
\hline 2 & $588 \mathrm{bp}$ & Inclusion of intron 4-5 \\
\hline
\end{tabular}

D

WT ...CLNASLLGGVLRR AKSKNGGRSLREKL... exon $4 \quad$ exon 5

MO .... CLNASLLGGVLRR STOP 
bioRxiv preprint doi: https://doi.org/10.1101/460105; this version posted November 2, 2018. The copyright holder for this preprint (which was not certified by peer review) is the author/funder, who has granted bioRxiv a license to display the preprint in perpetuity. It is made available under aCC-BY-NC 4.0 International license.

\section{Figure S4}

\section{A}
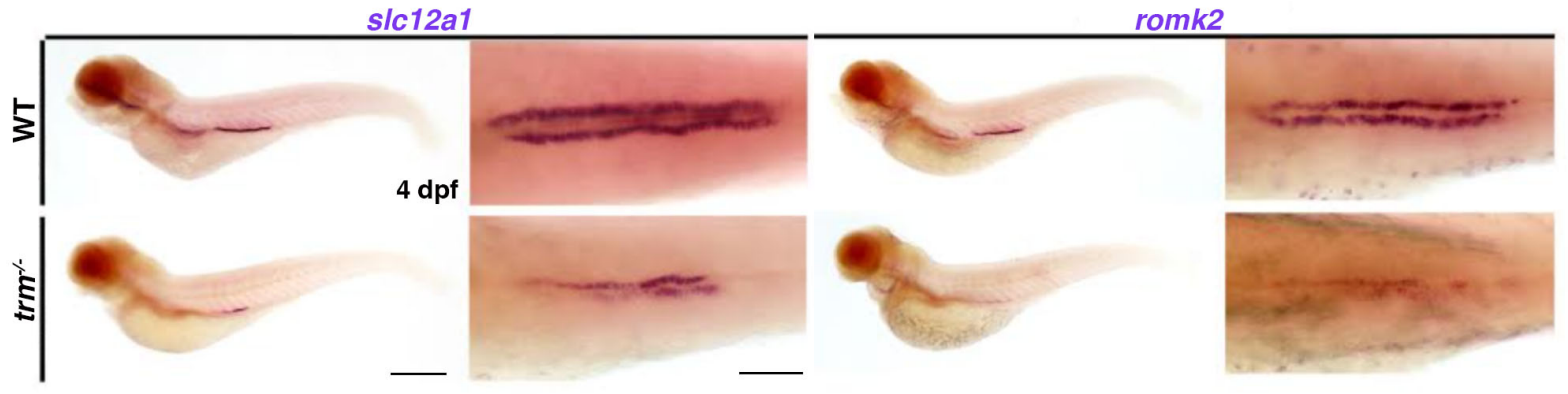

B

40 kD Dextran FITC
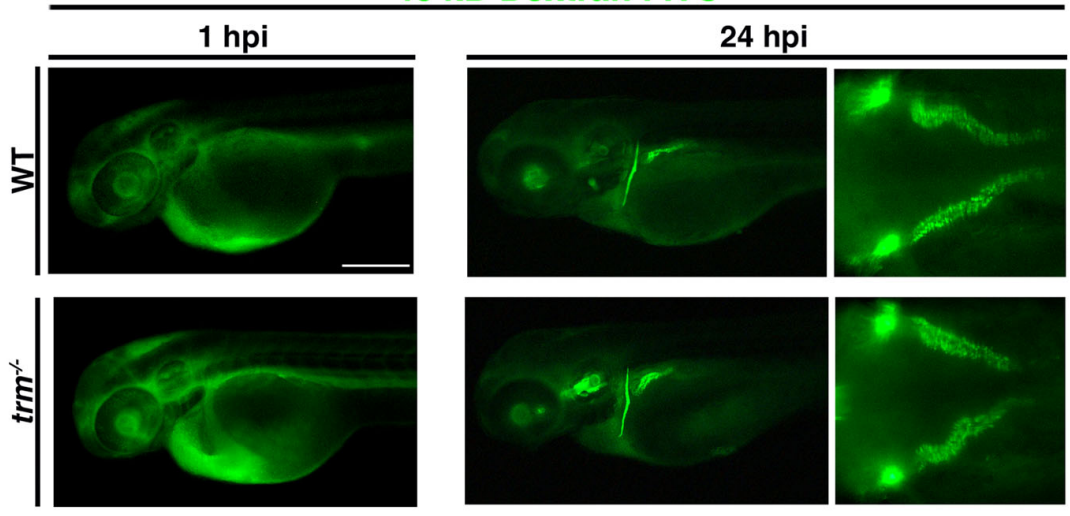

C

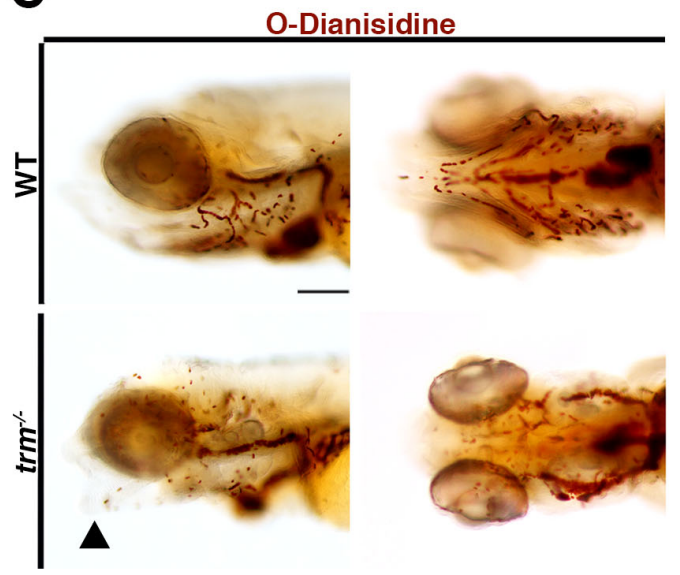


bioRxiv preprint doi: https://doi.org/10.1101/460105; this version posted November 2, 2018. The copyright holder for this preprint (which was not certified by peer review) is the author/funder, who has granted bioRxiv a license to display the preprint in perpetuity. It is made available under aCC-BY-NC 4.0 International license.

\section{Figure S5}
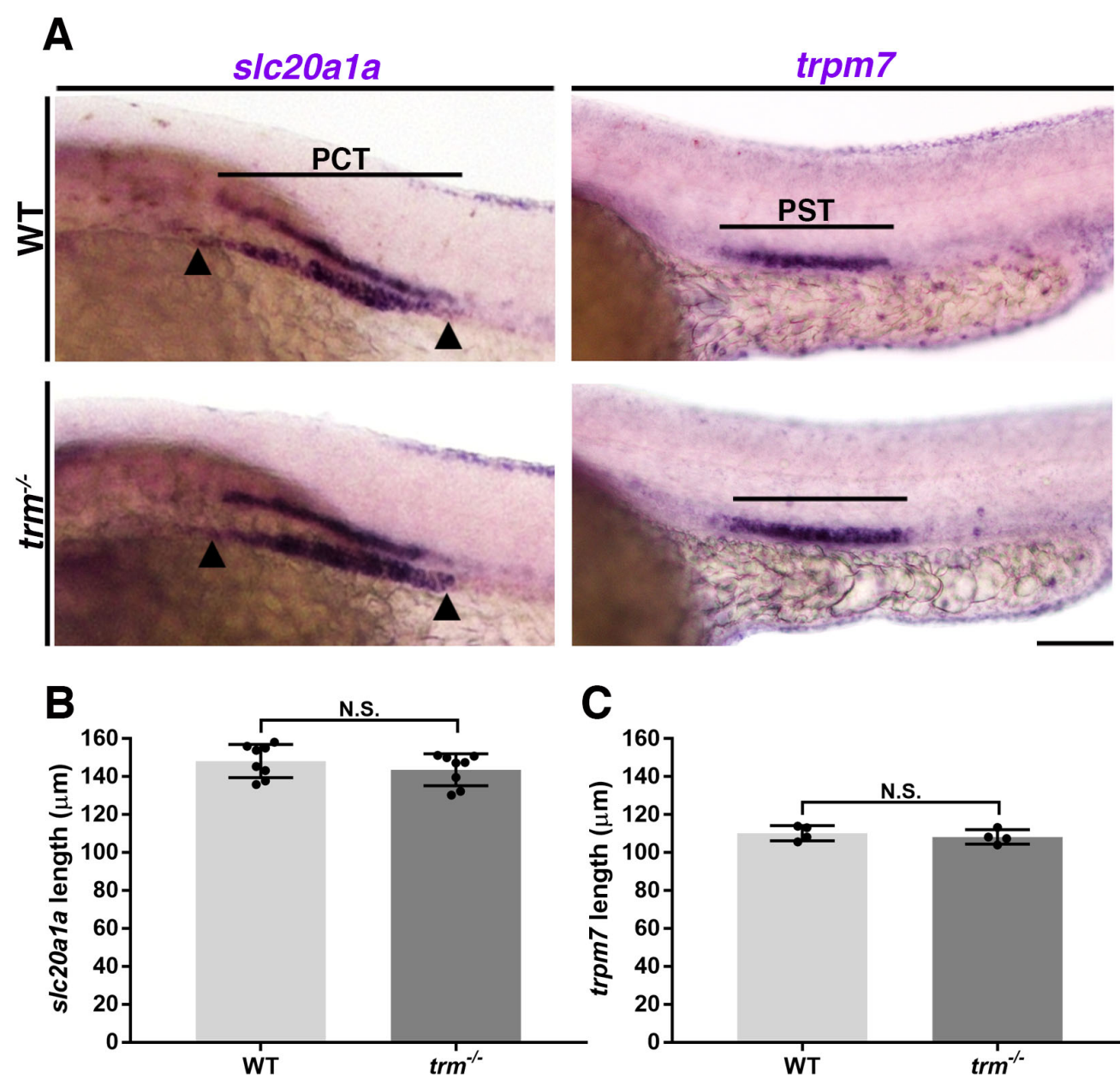

C

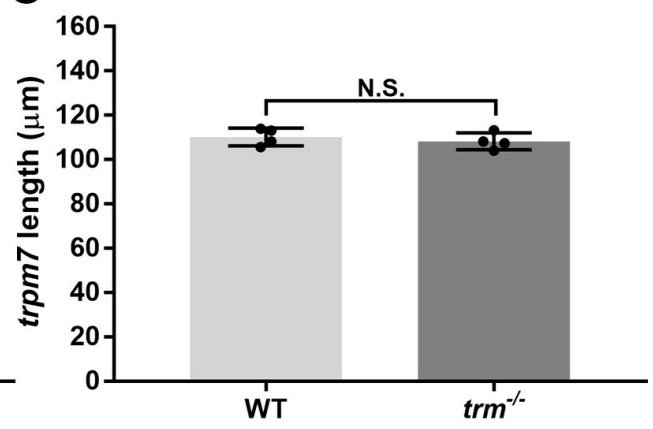

\section{D}
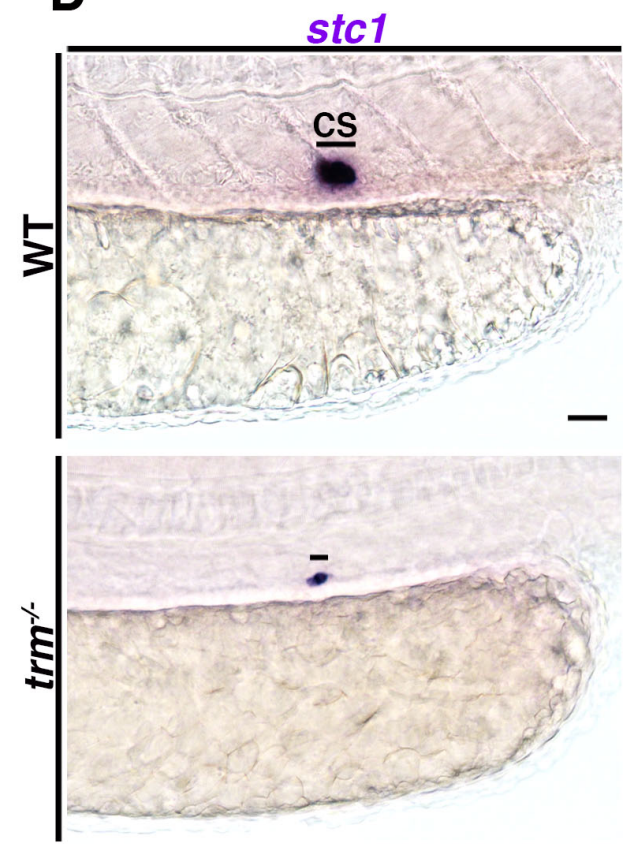